\title{
Learning in Foreign Cultures: Self-Reports of Learning Effectiveness across Different Instructional Techniques
}

\author{
Kumaran Rajaram ${ }^{1, *}$ \\ ${ }^{1}$ Nanyang Business School, Nanyang Technological University, Singapore \\ *Correspondence: Division of Strategy, Management \& Organization, Nanyang Business School, Nanyang \\ Technological University, 50 Nanyang Avenue, S3-B1A-04, Singapore 639798. Tel: 65-9455-3150. E-mail: \\ rkumaran@ntu.edu.sg
}

Received: July 25, 2013

Accepted: August 7, $2013 \quad$ Online Published: August 19, 2013

doi:10.5430/wje.v3n4p71

URL: http://dx.doi.org/10.5430/wje.v3n4p71

\begin{abstract}
Substantial numbers of Chinese mainland students are enrolled in overseas Western-based business courses but are dislocated from their home cultures. Business education curriculum and course designers need to understand how these students are best trained in western style education programs. Four-hundred students in Singaporean business training programs provided differential ratings of perceived learning effectiveness, plus dislocation measures of familiarity, comfort and ease of knowledge transfer for each of ten commonly used instructional strategies previously investigated by Rodrigues, four of which he termed "active" and six "passive". In terms of perceived learning effectiveness alone, Mainland Chinese students reported clear differences. In order of decreasing effectiveness, they reported lectures by instructors, case-studies, group projects, videos, guest speakers, classroom presentations, individual research projects, classroom discussions, computerized learning and lastly, reading textbooks. The study presents strategies and practices for facilitating effective learning for mainland Chinese students in western based education - choice of instructional techniques and mixtures, attention to students' cultural dislocation, comfort, familiarity, and ease of knowledge transfer.
\end{abstract}

Keywords: instructional techniques; learning effectiveness; cultural dislocation; knowledge transfer; comfort; familiarity

\section{Introduction}

The "Chinese Learner" has become a major focus due to the rapid increases in the numbers of mainland Chinese students studying in both Anglophone countries such as Australia, the United States, Canada and the United Kingdom as well as East Asian countries such as Singapore, Japan, Hong Kong, Macau and Korea (developed and modernized) and China and Taiwan (developing countries) (Ryan and Slethaug 2010; Coverdale-Jones and Rastall 2009; Clarke and Gieve 2006; Jin and Cortazzi 2006; Shi 2006; Turner 2006; Watkins and Biggs 1996, 2001). Asian-based educational institutions collaborate with overseas Western Universities to nurture a future workforce which includes a backbone of skilled talents. It is important for foreign students to adapt to Western-based educational approaches, hence acquire knowledge most effectively which assist them to cope, acquire knowledge optimally and excel in their studies. Moreover, a benefit aspired to is the ability for them to transit and work effectively in culturally diverse (Asian and Western) countries as future managers of global multinational corporations. Consequently, equipping them with appropriate knowledge in the most effective manner through their preferences of learning approaches in terms of their perceived learning effectiveness is imperative, as their future performance in organisations depends largely on the repertoire of knowledge and skills they have acquired.

China's national culture has changed progressively throughout a long history by adapting itself to evolving political, social and cultural demands. There are cultural challenges and adaptability issues involved in mainland Chinese students pursuing a Western-based education, notably, in a different country with varying proximity level of issues. The key challenges in today's international business education are to implement appropriate instructional strategies that facilitate student education (Tan, 2011). Offering quality education for international students entails a good understanding of the cultural aspects and effective methods of knowledge transfer which are integrated with optimal 
learning processes (Rajaram \& Bordia, 2011). Hence, the major issue here is an explicit understanding of effective instructional techniques suitable for mainland Chinese students. In this context, this research investigates issues in business study environments for mainland Chinese students in Singapore arising from cultural dislocation, by identifying students' perceived learning effectiveness in a variety of instructional approaches and its relation to cultural values.

This study is supposedly meant to be a re-visit of the similar sample type, much close to a longitudinal study. This is to further understand the students' reports of self-reported learning effectiveness, taking into consideration the rapid changing environment and its continuous influences over the years since the first research was performed quite some time back. The motivation was largely in experiencing the changes from the students' classroom behaviours and study patterns over the years, importantly its influences on the adoption of appropriate and effective instructional techniques.

\section{Theoretical Perspectives}

\subsection{Shifts in Chinese Cultural Learning}

Culture, communication and learning are intertwined and mutually dependent (Lum, 2006). To successfully maintain their reputations, international schools must strive to achieve a current and future cultural fit in their offshore operations to enable international students to acquire knowledge in the most effective manner which results in quality education (Bodycott and Lai, 2012).

Based on research conducted across 50 countries consisting of both Western and Asian countries, Hofstede (1980) developed a typology consisting of four cultural dimensions by which societies may be classified: individualism-collectivism (relating to interpersonal ties), power distance (relating to inequality), uncertainty avoidance (relating to dealing with the unknown and unfamiliar). He also discusses a fourth dimension of masculinity-femininity (relating to emotionally dissonant gender roles) which is outside the purview of this paper. Hofstede and Bond (1988) subsequently described another cultural dimension, Confucianism, which the authors claim is prevalent mainly in some Asian countries like Singapore, China, Hong Kong, South Korea, Japan and Taiwan. Confucianism is "more a tradition generally in Chinese Culture and nurtured by Confucius and Confucians" (Yao, 2000, p.17). It has changed throughout a long history by adapting itself to new political and social demands and has been termed a multi-dimensional concept (Shi, 2006). Hofstede and Bond (1988) claim this is related to certain behavioural and moral doctrines based on the teachings of Confucius. Ryan and Slethaug (2010) reported that the cultural framework of Hofstede (1980) charts the general characteristics of societies, hence its users should not generalize and stereotype the findings. But it can be challenged that the five cultural dimensions of Hofstede and associates are applicable if the context is used appropriately without generalizing and with explicit measurement variables and not generalizing it. The changes in China influence and shift the traditional cultural norms and values which affect the learning behavior. However, it can be argued that although the levels of the five dimensions may be shifted more or less, it is the range of shift that needs to be appreciated rather than stating that the complex cultural influences are now totally irrelevant which is similar to maintaining that the traditional cultural values that shape this framework is not totally applicable. Many scholars (Rajaram and Bordia, 2011; Ryan and Slethaug, 2010; Rajaram, 2010; Clark and Gieve, 2006; Gumingyuan, 2001; Nisbett, 2003) highlighted that students should not be labeled and confined by boundaries which causes myths to be generated about the groups of students and create false "reputations", however, explicit behavioral values and norms which influences preference of instructional techniques in terms can be studied through various unequivocal aspects, for example, in terms of comfort (power distance), familiarity (uncertainty avoidance) and ease of knowledge transfer (philosophy of Confucianism).

'Power distance captures the desire within a society for hierarchy versus egalitarianism' (Chan, 2006, p. 126). It refers to the amount of authority one person has over others and is linked to the importance given to hierarchy in a particular society. Applying this, it is apparent that the Chinese culture has a very high power distance, which can obviously be seen in the students' behaviour towards their teachers. They seldom challenge their inputs and they conform to those in an authoritative or designated higher position in the hierarchy. Chinese learners' unwillingness to participate can be related to their willingness to submit to authority (Wen and Clement, 2003). Shi (2006) states that "for most students, being knowledgeable, was still the most important criterion of good teachers" (p.137). This again emphasises the importance the Chinese students place on teachers' inputs and it clearly shows that they position themselves a level lower than their teachers. Chan (2006) reports that 'uncertainty avoidance' is related to a society's ambiguity. It refers to the measure of the level of comfort to handle conflicts and aggression in terms of ambiguous situations. Applying this to the Chinese culture, it comes across that there is a shift in the uncertainty avoidance level 
from high to moderate due to the rapid and vast social and cultural changes due to globalization and China's adoption of "open outlook" approach. This can be explained by the fact that as decades ago (in the phases of 1980s to 1990s), mainland Chinese students need to be closely guided and directed to carry out their assigned academic tasks. Many scholars argue that Chinese students still prefer the more passive way of learning, where a higher level of supervision is provided, and they are very unlikely to study on their own and independently (Chow 1995; Chan 1999; Nelson, 1995; Fox 1994; Atkinson, 1997; Carson, 1992; Oxford, 1995; Kumaravadivelu 2003; Newell, 1999). On the contrary, scholars (Yang 2009; Ryan and Slethaug 2010; Chan and Rao, 2009; Clarke and Gieve 2006; Rajaram 2010 and Shi 2006) reports that Chinese learners prefer student-centered to a teacher-centered approach, where lesser supervision is required from the tutors. Moreover, they are willing to participate in interactive and cooperative learning activities (although many studies are on language skills courses rather than business related courses), which it shows more willingness to be on their own and not so dependent. Hofstede and Bond (1988) found that the uncertainty avoidance dimension is less applicable in Confucian-based cultures, such as the People's Republic of China, South Korea, Japan, Hong Kong, Taiwan and Singapore (Rodrigues, 2004). Thus, it is expected that mainland Chinese students will adapt to Singapore's culture quite easily in terms of lifestyle, but are bound to have effectiveness issues which will surface in terms of the learning and acquiring of knowledge from the course curriculum developed from a Western country (Dimmock \& Leong, 2010). 'It is proposed that cultures that are based on the Confucian philosophy develop stability-generating systems that are considerably different from those generated in religion-based cultures' (Rodrigues, 2004, p. 612). Again, it is anticipated that conflicts will arise due to the Western-based education curricula emanating from a religion-based culture. The styles of delivery and methodology utilised will vary, thus having an impact on the acquiring of knowledge as well.

Chinese learners are largely perceived as passive rote learners among western scholars (Chow,1995; Biggs, 1996; Chan, 1999; Liu, 2006). The complex nature of these Chinese learners' cannot be oversimplified from a stereotypical generalization based on a solely culturally based notion of learning. However, the understanding of Confucian philosophical concepts is important to enable the Chinese students from mainland China who are deeply rooted in such values to transit and adapt to new learning environments. Although mainland Chinese students have fairly similar social value systems to those in Singapore, certain principles and values of Confucianism may cause conflicts and challenges in a Western-based curriculum because different instructional techniques are variously adapted to a western based approach. Stereotyped descriptions of instructional and learning approaches of mainland Chinese students cannot be generalized and based on scholars' reports decades ago due to the rapid and profound shifts in social, cultural and economic conditions in China. (Ryan and Slethaug, 2010; Chan and Rao, 2009; Hu, 2003; Jin and Cortazzi, 2006; Shi, 2006; Watkins and Biggs, 2001; Yang, 2009). The behavioral aspects of learning approaches and types of instructional techniques preferred (as they are linked to the assessment context) are intertwined with cultural values and norms. But this may add more complexity if these mainland Chinese students are studying in a western-based education course program coupled with cultural dislocation issues in a different proximity level of "Confucian heritage culture" (CHC) country (in this case - Singapore). Although Shi (2006) reports that the study in Shanghai shows that students "show little difference from their western counterparts by being active learners and preferring a more interactive relationship with their teachers" (Shi, 2006, pp. 122), this cannot be generalized, as the study was conducted in China with only a certain cluster of students. Factors such as comfort (power distance) and familiarity (uncertainty avoidance) tends to be different when students are pursuing a foreign-based program in another country. There are also other studies (Chan and Rao, 2009; Littlewood, 2009; Ryan and Louie, 2007; Yang, 2009; Watkins and Biggs, 2001; Jin and Cortazzi, 2006; Hu, 2003) which reports on teaching and learning practices, however, the explicit issues on a western-based curriculum where differing instructional approaches are to be undertaken in a culturally different Asian country (despite the "Confucian-heritage" similarities), appear not to have been examined to my best knowledge.

Although the mode of assessment shapes the general students' learning preferences. However, varying explicit cultural dynamics (rooted values, norms, culturally inclined behaviors, cultural dislocation issues) will still influence the teaching and learning approaches customised (example, varying level of proximity of guidance and directions for the same instructional approach for culturally diverse students) may also be expected to have differing influences on perceived learning effectiveness. This is especially essential at least until the prolonged exposure permits them to adapt their preferred or perceived styles of learning in accordance to the assessment modes adopted in different universities and their course programs. Arguably the three cultural dislocation dimensions-power distance, uncertainty avoidance and the philosophy of Confucianism-are recognized aspects of cultural diversity in internationally based educational and cultural environments but their influence on perceived learning effectiveness across the commonly used instructional techniques for mainland Chinese students has not been explicitly researched.- 


\subsection{An Educational Hub for International Students}

With China's growing economic and social advancements, the inflow of mainland Chinese is rising sharply with many beginning to explore opportunities outside their country. Singapore offers quality education with a conducive academic environment, plus cultural similarities that allow for easy adaptation because of cultural similarities between Singapore and China (Tsang, 2001). Furthermore, mainland Chinese tend to blend into Singapore's society more readily than into other Western countries (Tsang, 2001). These are probably some of many reasons for an increase in mainland Chinese students and academics coming to Singapore over the past decade (Bohm et al., 2002). China's economic liberalisation in opening to Western companies comes at an appropriate time as Singapore accelerates its next phase of attracting foreign talents to expand its national economy. Singapore's multiracial culture, which is dominated by a Chinese population, attracts the mainland Chinese largely due to the cultural and linguistic similarities. Moreover, Singapore is an excellent place for experiencing and embracing both Asian and Western values in recognised academic pursuits and stable employment.

Mainland Chinese have probably become the largest cluster of foreigners in the public and private international institutes and their adaptation to new cultural and learning/teaching environments has a direct impact on their academic performance. These students' main concern is whether they can achieve good academic results to increase their chances for further studies or employment in their desired careers after graduation (Bodycott, 2009; Bohm et al, 2002). As potential future managers, their performance in employment depends largely amongst other things are on how well they are trained and equipped with knowledge and skills in their courses of study and Chinese students who fail may be required to leave the country. Thus, doing well by learning effectively has both personal and organisational performance implications (Tsang, 2001) given the substantial differences in teaching/learning styles of Chinese vs. Western-based educational systems.

\subsection{Instructional Techniques}

Instructional techniques that are effective with students from one culture may not necessarily be effective with students from another (Johnson, 1991; Warner, 1991). Many scholars (for example, Kemp, 2010, Holland, 1989; Kolb \& Fry, 1975; Witkins et al., 1977) believe that some educational systems develop in harmony with local beliefs and practices and the systems in turn shape the students' learning preferences. Variations in teaching and learning practices around the world are essential to acknowledge as Western-based business education in Singapore becomes facilitated largely by multicultural faculty. Hence, instructional approaches with inherent active/passive differences (Rodrigues, 2004) do have impacts when examined in light of differing cultural dimensions and dislocation issues. Thus, the delivery of Chinese instruction using these techniques is not always identical to their delivery in Singapore.

\subsection{Perceived Learning Effectiveness among Different Instructional Techniques}

An extensive body of literature addresses teaching and learning approaches preferred by mainland Chinese students (Bu \& Mitchell, 1992; Biggs 1994; Chan, 1999; Coverdale-Jones 2006; Clarke and Gieve 2006; Jin and Cortazzi 2006; Louie 2005; Liu 2006; Littlewood 2009; Martinsons et.al., 1996; Ryan, 2005; Ryan and Hellmundt 2005; Ryan and Louie 2007; Ryan and Slethaug 2010; Rajaram and Bordia 2011; Shi 2006 and Turner 2006). However, the literature lacks a holistic approach integrating the explicit aspects of cultural dislocation values and learning principles which influences effective learning strategies for Western-based education, at least until these learners have adapted to the differing learning cultures after prolonged period, probably adjusting their preference of learning approaches due to the different assessment modes applied. Chan and Rao (2009); Chan (1999), Coverdale-Jones and Rastall, 2009; Bond (1992); Yang (2009); Biggs (1994); Ryan and Slethaug (2010) and Shi (2006) have called for such studies, but only students' learning styles and preferences for lesson delivery have been examined so far. There are no studies measuring perceived learning effectiveness for different preferences of instructional techniques in the context of a cosmopolitan country such as Singapore, although student preferences for different techniques may not necessarily equate to most effective learning.

There is literature evidence to support that cultural aspects are intertwined with the choice of learning/teaching approaches and styles, and hence values may influences the selection of approach by students, at least in the interim while adapting to another learning culture. For example, Johnson (1991) and Warner (1991) argue that a teaching/learning technique effective with students from one culture may not be effective with students from another. Some scholars believed (Holland 1989; Kolb and Fry 1975; Witkins et. Al. 1977) that fundamental differences in learning style lead to differing pedagogical preferences and that culture develop differing learning styles. Lindsay \& Dempsey (1983) have proposed that Asian and Western learners embrace differing pedagogical preferences. Others suggested (Pun 1989a; Jarrah 1998; Ladd and Ruby 1999) that Western learners accept involvement and learning through their own exploration while Chinese learners expect the teacher to lead, guide, and provide learning points. 
However, some scholars (Ryan and Slethaug 2010; Rajaram and Bordia 2011; Littlewood 2009; Ryan and Louie 2007; Rajaram 2010) disagree and argue that it is assessment, not traditionally stereotyped and perceived cultural aspects that influences the learning/teaching preference and thereafter, choice in their style/approach of learning approaches. Ryan and Louie (2007) argued that there should not be a fixated perspective that both "western" and "Asian" values can be legitimately described as discrete, homogeneous and unchanging. This encourages the labeling and positioning of clusters of students without examining the matter in relation to contextual teaching and learning issues (Kumaravadivelu 2003; Ninnes, Aitchison and Kalso, 1999) such as the influence on students' learning behaviours and attitudes of varying instructional approaches or learning tasks or types of assessment (Ryan 2002) or whether participative and interactive learning is facilitated or hindered (Littlewood 2009).

Historically, Chinese learning principles come from Confucius (Chan, 1999). For mainland Chinese students, education today still focuses on examinations which test the acquisition of a vast store of knowledge through rote memorization but at the expense of creativity (Chan, 1999). Chinese learners embrace a set of learning attitudes to how learning occurs and the rationale behind it. Some of these attitudes include focus, diligence, concentration and endurance of hardship ( $\mathrm{Li}, 2001$ ). Chinese learners often prefer not to express their views (Chan, 1999) so as to portray a modest outlook and as not to offend others. However, the myths about CHC learners as being passive, rote learners have been effectively debunked by (Watkins and Biggs 1996, 2001) and many others (Chalmers and Volet 1997; Chan and Drover 1997; Coverdale-Jones 2006; Greake and Maingard 1999; Hellmundt 2001; Jones 1999; Little wood 2001; Ninnes, Aitchison and Kalos 1999). But these views continue to be pervasive in the literature about the Confucian Heritage Culture (CHC) and Chinese students (Ryan and Slethaug 2010). Wen and Clement (2003), for example, characterize Chinese students as passive due to their unwillingness to participate in class and relate this to their willingness to submit to authority. Chinese students' learning characteristics have often been based on partial knowledge or misunderstandings which have led to negative stereotypes (Little wood 2009; Ninnes, Aitchison and Kalso 1999). Largely, CHC students' learning behaviors and beliefs are seen as the opposites of western academic values. These deficit views describe Asian students as being rote, passive and superficial learners lacking critical thinking skills (Ninnes, Aitchison and Kalos 1999; Ryan and Louie 2005; Kumaravadivelu, 2003). Due to the recent profound and rapid shift on the social and cultural aspects on Chinese learners from the rooted values of Confucius' teachings decades ago, it essential to re-examine the instructional approaches to be adopted for effective facilitation.

Students in some education systems desire greater control and personal responsibility in the learning process, whereas others prefer the teacher to provide the required structure (Dejoy \& Dejoy, 1987).

Rodrigues (2004, p. 609) highlights that:

Therefore, some students prefer passive instructional techniques, such as lecturing, wherein relatively low control and personal responsibility for learning is given to them, and some prefer active techniques, such as individual problem-solving projects, wherein relatively high control and personal responsibility for learning is given to them.

For this study, ten instructional techniques commonly used by business professors in colleges or universities identified by Rodrigues (2004) form the sample set for investigating students' perceptions of learning effectiveness related to the various instructional techniques.

\subsection{Active vs. Passive Learning}

Rodrigues categorized these ten instructional techniques as follows:

- $\quad$ Four active techniques: Case studies, Individual research projects, Classroom discussions and Group projects.

- Six passive techniques: Lectures by instructor, Reading textbooks, Guest speakers, Videos shown in the classroom, Classroom presentations by students, Computerised learning assignments.

In other ways of thinking, the ten commonly used instructional techniques can be categorised into active and passive based on the instructors' and students' frequency of participation. Some of these techniques require less student interaction, whereas others require more participation and exchange of perspectives between the instructor and students or among students themselves. Those instructional techniques that facilitate more participation via a two-way communication between the instructor and students or among students themselves are classified as active. In contrast, techniques that necessitate more of one way delivery by the instructors or acquiring information without much contribution and sharing from students are categorized as passive. Rodrigues (2004) noted that student frustration may be one of the outcomes if inappropriate instructional techniques (in terms of unfamiliarity, uncomfortable and techniques which students do not value in their perception) are used. He proposed that to be effective in cross-cultural teaching, instructors need to apply suitable techniques by which the students learn best and gain optimal knowledge 
and that the selection of techniques depends on where the instructors will be teaching or the country or countries from which the foreign students came and what subject matter instructors will be teaching.

Mainland Chinese students bring certain distinctive values from their cultural backgrounds but there are noticeable differences in the teaching/learning methodologies used between China and Singapore. Hence, maximizing student learning requires selecting a mix of instructional techniques that best help them shift from their Confucian heritage toward Western-based educational curricula and business practices. This enables both matching teachers' delivery approach with students' preferences and shifting students' preferences to fit based on the types of assessment adopted.

\section{Current Studies}

Hofstede and associates are among the leaders in the field of cultural studies. Three of their cultural dislocation aspects (power distance, uncertainty avoidance and the philosophy of Confucianism) are used to frame the cultural context of this research.

Morey and Frangioso's (1998) learning effectiveness principles were adapted by incorporating learning constructs of understanding, skills, processes and inferred learning effectiveness elements (self-reported). The cultural dislocation constructs - comfort (in terms of power distance), familiarity (in terms of uncertainty avoidance) and knowledge transfer (based on the philosophy of Confucianism) - were based on Hofstede's (1980) and Hofstede and Bond's (1988) cultural dimensions. Table 1 reports how the three dislocation aspects are operationalised and summarizes how students reported each of the ten instructional techniques examined.

Concepts and terms such as "power distance”, "uncertainty avoidance”, and "Confucian learning principles” are scarcely in the daily vocabulary of business students studying overseas. These rarified concepts were thus operationalised using words and terms which were more familiar to students and for which precedents existed in the cultural dislocation literature.

Table 1: Dislocation Aspects, Operational Measures, and Research Precedents

\begin{tabular}{lll}
\hline Dislocation Aspect & Operational Measures & Precedents \\
\hline (What theory claims) & $\begin{array}{l}\text { (What students } \\
\text { were asked to report) }\end{array}$ & (Previous use of similar terms) \\
Power Distance & Comfort & Chan (1999), pp. 300-301 \\
& Nield (2004), pp. 190 \\
Uncertainty Avoidance & Familiarity & Chan (1999), pp. 302-303 \\
& & Chow (1995), pp. 12-13 \\
& Knowledge Transfer & Shi (2006), pp. 137-138 \\
Confucianism & & Tweed \& Lehman (2002), pp. 85-86 \\
& & Tweed \& Lehman (2003), pp. 148-149 \\
\hline
\end{tabular}

Power distance concerns how people perceive and cope with inequities in the distribution of power (Rodrigues, 2004). Some instructional techniques intentionally minimize the power distance between learner and instructor (or among learners) while other techniques emphasize the power disequilibrium. Instruction by its very nature requires skillful challenges to students' comfort zones. Chow (1995) argued that instructors' directive involvement relates to students' varying comfort level -- in turn --influencing students' perceived learning effectiveness. In a study of 167 mainland Chinese students with English majors specializing in English language and literature, it was reported that the students preferred a student-centered approach to a teacher-centered approach; they were willing to participate in interactive and cooperative language learning activities yet expect teachers' guidance to help them pass tests and provide them with detailed and clear notes (Shi, 2006). Within reason, the greater the instructor involvement, the greater the comfort, hence the greater the learning effectiveness. Applying his logic, students reported their comfort level with each of the ten instructional techniques as a proxy measure of power distance.

Chan (1999) maintained that uncertainty avoidance refers to ease in handling conflicts and aggression in ambiguous 
situations. Among these ten instructional techniques are varying opportunities for potential conflict, aggression, and ambiguity between instructor and learners or among learners themselves. This can be emphasized by Shi's (2006) study where the mainland Chinese learners "wanted their teachers to be light-hearted and use various teaching activities, on the other hand, students also expected teachers to help them pass tests and provide them with detailed and clear notes" (pp. 138). Chan (1999) argued that these uncertainties are more avoidable among familiar instructional techniques whereas other techniques which are fraught with ambiguity, aggression, or conflict, are unfamiliar and their uncertainty is to be avoided in favour of greater perceived learning effectiveness. Thus, students reported on familiarity as a measure of the uncertainty avoidance attached to each instructional technique.

A distinctive learning style emerges among people sharing a common historical and geographical setting because they must collectively adapt to a unique set of environmental demands (Shade, 1989b). However, this has been challenged by other scholars (Ryan and Slethaug; Chan and Rao 2009; Rajaram, 2010; Yang 2009 and Littlewood 2009) emphasising that the choice of learning styles/approaches are fundamentally driven by assessment modes rather than a particular cultural heritage and values. But this is again to be questioned as studies show that there is some level of cultural intervention, especially the interim phases as well as at least until the learners have totally adjusted to the new learning culture which only happens after prolonged period of time. Characteristic learning styles of a nation/culture are also institutionalized and reinforced through its child rearing practices and education systems (Rodrigues, 2004). For example, "Chinese students did not think that having their own opinions was important for a good learner” (Shi, 2006). Wen and Clement (2003) reports that Chinese students' unwillingness to participate in class can be related to their willingness to submit to authority. These are social and cultural values/norms that are embedded in individuals' behavior which influences their learning attitudes and behaviours. The cultural backgrounds of learners do influence their levels of knowledge acquisition, particularly in terms of academic learning (Tweed \& Lehman, 2002). Thus knowledge transfer is held as a focal dimension of Confucianism and there is a governing view that each society has a unique set of cultural values (although it is not fixated and changes) that guide managerial belief and actions illustrated in workplace practices and business relationships (Adler at al., 1989). Similar logic can be applied to classroom environments where a specific cultural group of students presents a specific trend of learning behaviours and styles. Many studies (Ryan and Slethaug 2010; Littlewood 2009; Chan and Rao 2009; Jin and Cortazzi 2006; Yang, 2009; Shi 2006; Ryan and Louie 2005; Kumaravadivelu 2003; Hu 2003) on Chinese learners are performed however, specifically identified key cultural dislocation notions influencing learning/teaching approaches in pursuing a western-based program in a developed cosmopolitican countries has limited evidence in research.

\section{Research Questions}

From the conceptual framework, four broad research questions addressed the key issues and served as a roadmap. The interworkings between perceived learning effectiveness, comfort, familiarity and knowledge transfer were formulated into four research questions addressing the study's key objectives:

\subsection{Cultural Dislocation Aspects}

1. How does the power distance of a learning technique relate to its learning effectiveness for mainland Chinese tertiary students in business courses? Do techniques which students see as reflecting greater power distance (hence more comfortable) also result in greater perceived learning effectiveness, and are techniques which reflect less power distance (less comfortable) also associated with lesser perceived learning effectiveness?

Chan (1996) described the Chinese culture as reflecting high power distance, which is obvious in students' behavior towards their teachers. Students seldom challenge teacher inputs and they conform to authoritative roles in the instructional hierarchy (Chan, 1991). Hence, students generally regard high power distance learning settings collectivist mindsets as "comfortable" (Hofstede, 1991). Recent studies by scholars (Yang, 2009; Rajaram, 2010; Chan and Rao 2009) shows that students are more willing to participate in interactive learning (although many studies are on language skills courses), where they willing to work on their own, hence making them not so dependent (means involves lesser power distance for them to be "comfortable").

2. How do the uncertainty features of learning techniques relate to their learning effectiveness? Do techniques where students can avoid uncertainty because they are more familiar also result in greater perceived learning effectiveness, and are techniques with uncertainties that cannot be avoided because of the nature of the technique and in the case of PRC (People's Republic of China) students, where the technique is also relatively unfamiliar in their 'back home' classrooms also associated with lower perceived learning effectiveness? 
The literature argues that Chinese students are accustomed to being closely guided and directed to carry out their assigned academic tasks. Chan (1999) reported that these students prefer ways of learning which do not require active engagement by the student, rather-receptive way of learning, where a higher level of supervision (hence lesser uncertainty avoidance) is provided, and they are unlikely to be on their own and independent. In contrary, scholars (Rajaram, 2010; Ryan \& Slethaug, 2010) argued that these mainland Chinese students prefer "student-centered" to "teacher-centered" approaches where tutors provide lesser supervision (hence means higher uncertainty avoidance). However, it was pointed out that by Rajaram (2013, in Press) and Louie (2005) that students have different "cultural baggage", where the learning attitude and behavior of students differ whose parents are from a more advanced province and another who are from a rural village.

3. How does the influence of Confucianism of various learning techniques relate to their perceived learning effectiveness? Do techniques which students view as strongly Confucian (hence ease of knowledge transfer from teacher to student) result in higher perceived learning effectiveness compared to than techniques which are regarded as "less Confucian" than those which are associated with lesser perceived learning effectiveness?

Confucian learning principles have gone through some profound rapid changes of China's social and political demands. From largely inclined towards passive and repetitive learning approaches, where it generally limits the students' involvement and participation in classroom activities, for example, sharing of opinions, contributing to discussions and challenging norms (Bu \& Mitchell, 1992; Chow 1995; Carson 1992; Atkinson, 1997; Fox, 1994; Kumaravadivelu, 2003) to scholars (Chan 1997; Ryan and Slethaug, 2010; Shi, 2006; Clarke and Gieve 2006; Yang 2009; Chan and Rao 2009) reporting that Chinese learners are highly active; prefer a student-centered approach to a teacher-centered approach and willing to participate in interactive and cooperative learning activities. However, a majority of these specific findings of shifts in learning approaches are reported largely from Chinese learners from China and Hong Kong, but not specifically in pursuing a western-based (refers to the degree programs offered by Western universities, example from the UK, Australia, the USA, etc. These courses are conducted in Singapore with local educators' facilitation) studies in a cosmopolitan and modernized country (for example, Singapore). On the contrary some other scholars (Chan 1991; Chow 1995; Nelson 1995; Flowerdew, 1998; Oxford, 1995) often implicitly or explicitly claimed that the 'Chinese culture of learning' is heavily influenced by Confucianism. Newell (1999), Chow (1995) and Chan (1999) described that Confucian teaching and learning styles to involve challenges such as lack of abstract thinking, constraints on behavior caused by embarrassment, over-emphasis on concrete examples, lack of creativity, and the need to compromise in group situations. These claims were challenged by other scholars (Ryan and Slethaug 2010; Rajaram and Bordia 2011; Shi 2006; Ryan and Louie 2007; Littlewood 2009) who caution not to stereotype Chinese learners' learning approaches and not to describe them as discrete, homogeneous and unchanging. Hence, students generally regard knowledge as "easier to be acquired" via instructional techniques with higher influence of Confucianism (that has shifted its cultural values and beliefs over the recent years due to China's progressive openness and growth).

\subsection{Active/Passive Instructional Techniques}

4. Do students rate the six passive techniques (lectures, reading textbooks, guest speakers, videos, classroom presentations and computerized learning) overall (in terms of perceived learning effectiveness, comfort, familiarity and assumed knowledge transfer) differently from the four active techniques (case-studies, individual research projects, group projects and classroom discussions)?

Chan (1999) and Chow (1995) both reported that mainland Chinese students prefer to learn by repetitive learning. In contrast, scholars (Rajaram 2010; Littlewood 2009; Chan and Rao, 2009; Rajaram and Bordia 2011; Hu 2003; Yang 2009; Jin and Cottazzi 2006) reported that these students have shifted their preference towards a more active and interactive style of learning approaches. This is re-iterated where Shi (2006) reports the Chinese students "show little difference from their western counterparts by being active learners and prefer a more interactive relationship with teachers" (p. 122). But that does not necessarily mean that these students would learn effectively from their preferred style of learning techniques when measured under varying cultural dislocation aspects such as power distance (comfort), uncertainty avoidance (familiarity) and Confucianism (ease of knowledge transfer) across the ten instructional techniques.

Moreover, the lecture -- categorised as 'passive' by Rodrigues (2004) -- was the most predominantly used instructional technique that the students had exposure to since their high school days (Chow, 1995). 


\section{Method}

5.1 Motivations Driving the Choice of the Field Investigated and Its Characteristics with Respect to Instructional Techniques (Business Studies)

According to the Ministry of Education's annual statistical 2011-2012 report, business education attracts the largest pool of international students to Singapore. From this cluster, the students enrolled in undergraduate studies are the largest cohort. Among these international undergraduate students, the biggest cohort was mainland Chinese students. Therefore, it is only practical to shed some light on this group of students. Private international schools are taken as the focal platform because this is an up-and-coming group, which attracts a reasonably large percentage of foreign students, with a rising trend. This is based on the annual statistical data provided by the Ministry of Education (MOE) for Singapore for the years 2009-2012. The yearly growth in enrolment of international students in business courses is a clear indication of its continuously growing popularity. This phenomenon presents both opportunities and challenges. To deal with the intensifying challenges of these international students and their educational needs, most private institutions offer a wide range of business courses in comparison to other specialised course programs. For example, the ratio of business courses offered by other specialised course programs in the three identified institutions is approximately 1:3. This is a clear sign of the increasing enrolment in business courses among the international students, especially the mainland Chinese students. The high demand may be due to the type of subjects that are being offered in these business course programs. These subjects are more likely to be within the students' interest, liking and ability to cope.

One of the key challenges in today's international business education is the ability to implement appropriate instructional strategies understanding the cultural dislocation elements that facilitate student education. Offering quality education for international students entails a good understanding of the cultural aspects and effective methods of knowledge transfer through appropriate instructional strategies, integrated with optimal learning processes. Thus, the key issue here is an explicit understanding of effective instructional techniques which are suitable for these mainland Chinese students. In this context, this research serves to address the prevailing issues surrounding the influence of cultural values on students' perceived learning effectiveness via the most appropriate usage of instructional techniques.

\subsection{Participants}

The study's target population consisted of mainland Chinese students pursuing degrees in Western-based undergraduate business studies in Singapore. Three groups of student experience were categorized: a) students who had been in their course of undergraduate studies for less than a year; b) students who had been in their undergraduate studies for at least two years and were at least halfway through the course program; and c) students who were in the last six months of their undergraduate studies.

Seven schools representing $41 \%$ of Singapore's 17 private business schools (institutions which were issued four year operating licenses) were identified. These particular seven institutions were selected to ensure that all ten instructional techniques were frequently used by the business faculty, particularly in all the undergraduate courses in which these students were enrolled.

Of the 2,102 students enrolled in the seven schools, 447 returned questionnaire materials. Of these, 400 contained no missing data and were otherwise complete. The respondents represented China's geographic diversity with origins in four regional quadrants: North (101 students), South (102 students), East (96 students) and West (101 students).

In order to recruit only qualified students, all seven institutions have high entry requirements for their diploma, undergraduate and postgraduate courses. These seven institutions were good representations of typical private institutions in Singapore, especially in facilitating the teaching delivery and curriculum to mainland Chinese students. Their Western-based academic curricula were similar to a majority of Australian, United Kingdom, United States and Canadian institutions in the West. In addition, the institutions provided a representative match in terms of entry criteria, ethnic composition of academic staff, teaching/learning methodologies, how courses were run, teacher/class ratios and standards of course materials.

\subsection{Procedures and Analysis}

The mixed method study consisted of a pilot study in which 20 mainland Chinese business students helped to focus and refine learning effectiveness issues which formed part of the subsequent questionnaire administered to all eligible students throughout the seven institutions. Short descriptions of what is typically involved in the different instructional techniques were briefed prior to the interviews conducted to ensure the participants were providing inputs with the same instructional experience. 
The method of data analysis was similar to that used by Rodrigues (2004), who examined the impact of western national culture on the importance that groups of internationally mixed students placed on the instructional techniques. The pilot study, data were qualitatively analysed with the use of consensual qualitative research (CQR) (Hill, Thompson \& Williams, 1997). The CQR team consisted of two primary researchers and one external auditor. The culturally diverse team formation facilitated the data analysis with extensively diverse perspectives. Consultation with the auditor enabled the assessability on the appropriateness of the interview protocol. The principal researcher analysed the key themes from all the interviews and for each instructional technique. Main themes were classified into broad clusters for compilation. For statistical analyses, SPSS v16 facilitated computation of the frequencies, means, standard deviations and correlations. For each of the ten instructional techniques, their respective measures of learning effectiveness, comfort, familiarity, and ease of knowledge transfer were the means of 400 students' ratings.

\section{Results}

\subsection{Qualitative (Pilot) Study: Interviews}

6.1.1 Self-reports of Perceived Learning Effectiveness across Different Instructional Techniques

\section{Lecture}

Three (out of 20) pilot study students had reported that the lecture approach enabled understanding and easier learning. Moreover, they indicated that this mode enabled the students to acquire more knowledge, as the information delivered came directly from the lecturer, who was an expert in that field. However, two of the students had highlighted that it largely depended on the approach of the lectures and how the information was presented: 'It depends on the lecture's delivery mode ...'. Still, lectures were ranked at the top-rated positions. However, this lecture approach is facilitated with certain level of interactive aspects incorporated with more of a participative style. But largely it came across that this mode is preferred as majority of students are still inexperienced (undergraduates) and feel more comfortable with information being taught just as what other culturally diverse students may have reported.

\section{Case-Study}

Eleven (out of 20) pilot participants had reported that they believed case study approach improved their critical and analytical thinking skills. This was vividly illustrated by one of the interviewees: 'It challenges us more and makes us develop what we have learned. I think I can learn from developing from the current knowledge ...'. Evidently mail study respondents agreed and rated case studies at the top of the learning effectiveness spectrum.

\section{Group Projects}

Some pilot students had reported that group projects allowed them to learn much better from others' perspectives in problem solving: 'I feel that with more views inputted on one given problem, it allows me to learn much more effectively as discussing with my group mates allows me to refresh and learn from them as well .... Other pilot students indicated that it also allowed them to compare differing views and make well-thought through decisions: '..When peers have different opinions, then we share why we think in that specific manner and usually learn from each others' views ...'?

\section{Videos}

Six pilot students had reported that the video approach was effective as it allowed knowledge acquisition in a different yet interesting manner, by visualising and listening: '..I am able to better understand the theory concepts...I am able to see and appreciate the real operations which happen in the industry ...'.

\section{Guest Speakers}

Six pilot students had agreed that guest speakers facilitate understanding the contents in much greater depth: '..It allows me to refresh what I already know and helps me to understand the contents with much better depth ...'. Students were able to learn by listening to the experiences directly from the industrial practitioners and experts in the field: 'I feel that I could learn something new from the people from the industry directly and how they have handled the real-time issues ...'.

\section{Classroom Presentation}

Most of the pilot students had agreed that the classroom presentation assisted them to develop their self-confidence as they were exposed and literally forced to present the digested contents after much analysing: '..I am much more 
comfortable and confident as it literally forces me to understand the contents well and thereupon express my points by putting forth my thoughts and ideas...'. It also allowed the students to learn from their mistakes, with the postpresentation feedback from both their peers and the lecturer. These students reported that they could share and present their opinions, which they were not experienced during their high school days in China: '..It allows me to express my opinions and see what others have to say. The teachers also come in to give their views and could tell whether we are right ..'.

\section{Individual Research Projects}

Three pilot students had mentioned that the individual research project facilitated independent learning. It allowed students to acquire knowledge by handling projects individually, without the help of their classmates: '..There are not many avenues for me to share my views with others and to listen to what others have to say about my work, as we are all alone in doing the assignment ..'. This helps them to learn much better as it allows them to be independent, thus helping them to learn in an uncomfortable and challenging situation.

\section{Classroom Discussions}

Classroom discussions had helped the pilot students to acquire and learn information much more easily. A few students reported that this instructional technique allowed the students to increase their awareness of the subject matter by relating to their past experiences: 'We do share and link up the past experiences that we have, which allows me to link up to the knowledge and information that is being taught ...'. Students mentioned that learning through making mistakes did improve their confidence level.

\section{Computerised Learning}

The computerised learning approach facilitated the pilot students to develop their ability to be flexible. Four students agreed on this point. The ability for students to learn in a flexible mode allowed them to manage their own time and to be independent: 'It does allow me to share my opinions freely in my own free time, but I find that the expressing of ideas done via the e-platform, by the written mode-I have my own difficulty, and it has its own limitations as well...'. A few students reported that although it offered flexibility, effectiveness of the learning in terms of quality delivery of information was affected: '..Although it provides the flexibility of learning at any time, but I find it is not very user-friendly in terms of my learning and acquiring of more knowledge....'.

\section{Reading Textbooks}

A number of pilot students had supported both perspectives in regard to the quality of learning by the instructional approach of reading textbooks. On one hand, 11 students had reported that the quality of learning via reading textbooks was linked to their ability to learn and acquire more information. It also reportedly facilitates better understanding, with the ability to acquire specific details. Furthermore, this approach of reading textbooks did assist them to enhance their language proficiency and vocabulary: 'Can improve a lot as by reading, I learn new words and my vocabulary improves, as well..'. On the other hand, eight students had reported that the quality of learning was affected as these students found it a challenge to comprehend the written language in the textbooks. Five of them highlighted that they were unable to grasp the contents with ease due to the level of difficulty present in the technical jargon. Overall, the main study students agreed that reading texts resulted in the lowest learning effectiveness.

\subsection{Qualitative Findings - Summary}

A total of 16 different concepts on measures of learning effectiveness were identified by pilot participants: (a) Effectiveness; (b) Quality; (c) Scope of knowledge; (d) Adaptability to learning; (e) Knowledge gaining; (f) Control over learning; (g) Security; (h) Ease of mind; (i) Awareness of subject matter; (j) Efficiency in learning; (k) Level of understanding; (l) Attractive learning environment; (m) Applicability of knowledge; (n) Flexibility (o) Learning environment; (p) Compatibility. These 16 concepts were drafted into 24 interrelated questions and each was measured as a 5-point Likert item. Some of the 24 questions are asked in more than one way to slightly oversample the 16 concepts. Collectively, the items were summed to yield a scale of learning effectiveness with an overall alpha reliability of 0.91 . Three further questions operationalized comfort (as a proxy for power distance), familiarity (as proxy for uncertainty avoidance) and ease of knowledge transfer (as proxy for Confucianism) also as 5-point Likert-like items with one item each per instructional technique. For convenience, all scale totals were divided by the number of items comprising each so that learning effectiveness, comfort, familiarity, and ease of knowledge transfer are all represented as 1-to-5 scales.

\subsection{Quantitative Study - Questionnaires}

The questionnaire was designed to parallel a similar research study by Rodrigues (2004). The approval for the study 
was obtained from the University of South Australia's ethics committee. The questionnaire was drafted in English since all the students pursuing business courses were required to have a minimum International English Language Training System score of at least 6.0 (indicating "good proficiency" in English). Short descriptions of what is typically involved in the different instructional techniques have been provided in the questionnaires to ensure the participants were rating the same instructional experience. Questionnaire distribution was carried out through four modes-face-to-face, email, and surface mail—and the survey was carried out over the telephone as the fourth approach. Survey returns from each distribution mode were: face-to-face: 248; email: 83; surface mail: 29; and telephone: 40. Assigned external consultants managed all questionnaires to avoid ethical issues of bias, favouritism and the obligatory need to respond in a particular manner. To address the issue of anonymity in handling the raw data compilation, external consultants used a coding system to transfer responses into numerical scores. To increase the participation rate, students who completed and returned the questionnaires distributed either by hand, by email or by surface mail were informed of their chance of winning the 'lucky draw' book vouchers. This also included those who participated in the survey via the telephone mode. A total of 50 vouchers, each worth $\$ 20.00$, acted as incentive for participation.

\subsubsection{Perceived Learning Effectiveness across Different Instructional Techniques}

Figure 1 presents how the 400+ mainland Chinese students collectively rated the learning effectiveness of each of the ten instructional techniques. Perceived effectiveness for each technique was explored by examining its mean and its standard deviation (for overall consensus).

\section{Mean \\ (Learning}

Effectiveness)

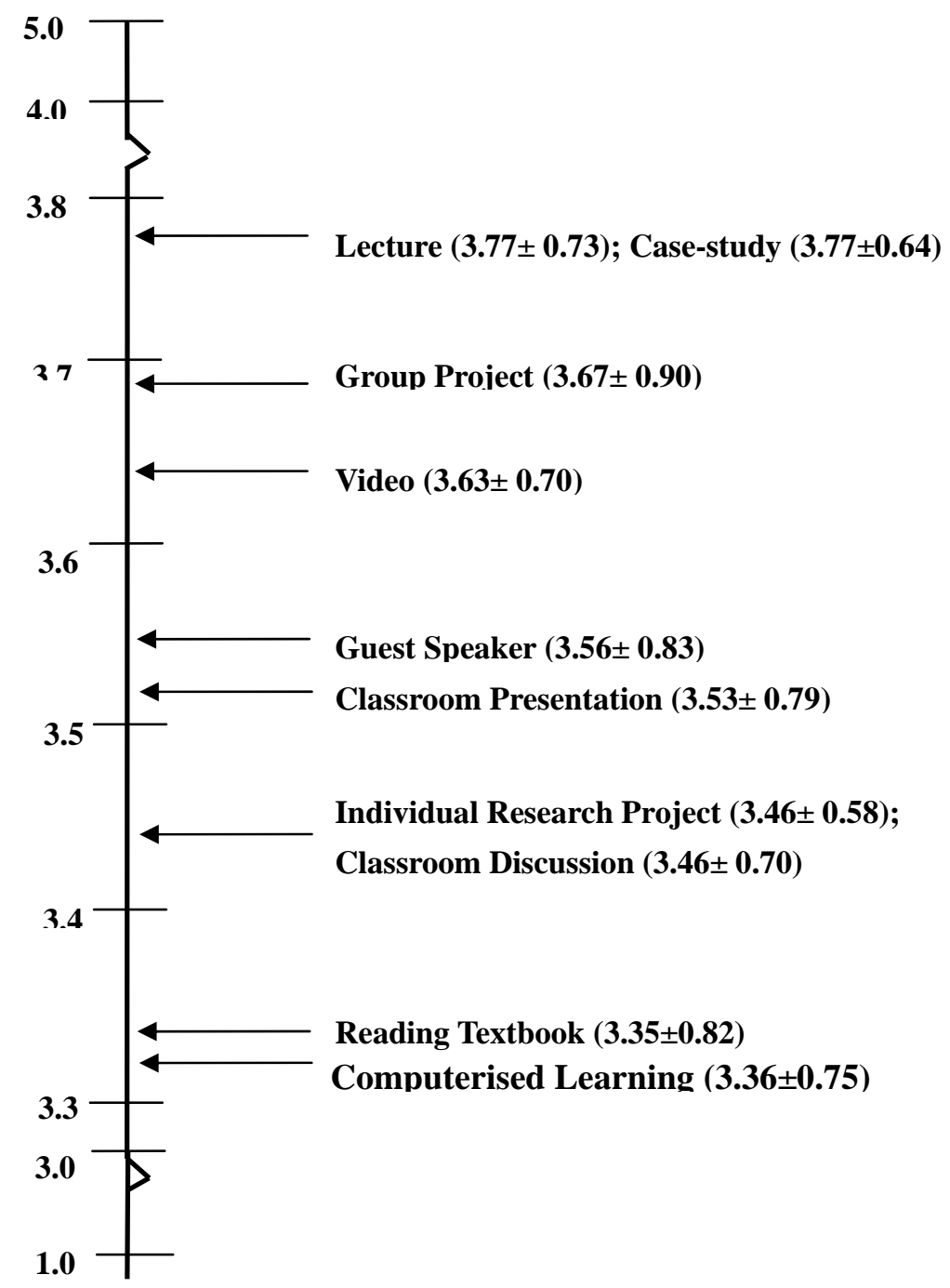

Figure 1: Learning Effectiveness Ratings for Ten Instructional Techniques (Mean \pm StdDev) 
Figure 1 shows that means for the 10 instructional techniques occupied a comparatively narrow range (3.35 to 3.77) of the available 1-to-5 effectiveness spectrum. Lectures and case studies received the highest learning effectiveness ratings (tied at 3.77) followed by group projects (3.67), videos (3.64), guest speakers (3.56), classroom presentations (3.53), individual research project and classroom discussions (tied at 3.46), computerized learning (3.36, and lastly, reading textbooks (3.35). Pilot study interviews had foreshadowed these numerical results where large fractions of 20 pilot participants reported that they learned effectively from lectures (which were already familiar to them) and case studies (which required them to think critically and to apply concepts).

Even though the main study students were presented with a 5-point scale to report their agreement or disagreement about the learning effectiveness of each instructional technique, their mean ratings subtended only about a $10 \%$ fraction of that range (3.35 to 3.77). Each technique received occasional extreme ratings (strongly disagree or strongly agree) by at least a few students, but their overall means clustered in the third quartile of the scale and all ten techniques were rated above its "neutral" mid-point. No one instructional technique should be claimed as "most effective" or "best" for mainland Chinese students, although they generally preferred rote learning approaches.

\subsubsection{Correlations among Learning Effectiveness, Comfort, Familiarity and Knowledge Transfer}

Not surprisingly, greater learning effectiveness is generally associated with lesser comfort (Vygotsky, 1997; Vygotsky, 2004), greater familiarity, and greater ease of knowledge. Means for the ten techniques (as rated by all 400 students, Table 3) were intercorrelated and Table 2 reports these correlations. All correlations are statistically significant, even though these data are now means for the 10 techniques aggregated across all students.

Table 2: Correlations among Learning Effectiveness, Comfort, Familiarity and Knowledge Transfer

\begin{tabular}{lllll}
\hline & LE & Com & Fam & KT \\
\hline $\begin{array}{l}\text { Learning } \\
\text { Effectiveness }\end{array}$ & --- & & & \\
Comfort & $.614^{* *}$ & --- & & \\
$\begin{array}{l}\text { Familiarity } \\
\begin{array}{l}\text { Knowledge } \\
\text { Transfer }\end{array}\end{array}$ & $.564^{* *}$ & $.759^{* *}$ & --- & \\
\hline$* * \quad(\mathrm{P}<0.01) ;{ }^{*}$ & $(\mathrm{P}<0.05) ; \mathrm{n}=10$. & $.660^{* *}$ & $.769^{* *}$ & -- \\
\hline
\end{tabular}

\subsubsection{Learning Effectiveness and Comfort}

Comfort had the highest association ( $\mathrm{r}=.614)$ with perceived learning effectiveness. Techniques which these Chinese students assessed as "comfortable" (lectures, case studies, group projects, etc.) reflected the greatest sense of belief in, assumption about learning effectiveness, while less "comfortable" techniques (reading texts, computerized learning, classroom discussions) resulted in lower reported perceptions of learning effectiveness reports. Figure 3 shows these results for all ten techniques. The vertical axes of Figures 3, 4, and 5 are identical to the expanded version in Figure 1 above.

Overall, students rated lectures and case-studies as the most effective learning techniques, followed by group projects, classroom presentations, videos and guest speakers, classroom discussions and individual research projects, while computerized learning reading texts were seen as least effective. Similarly, students reported that they were most comfortable with lectures, followed by case-studies, group projects, classroom presentations, videos, guest speakers, classroom discussions, computerized learning, then reading textbooks, while they were least comfortable with individual research projects. 


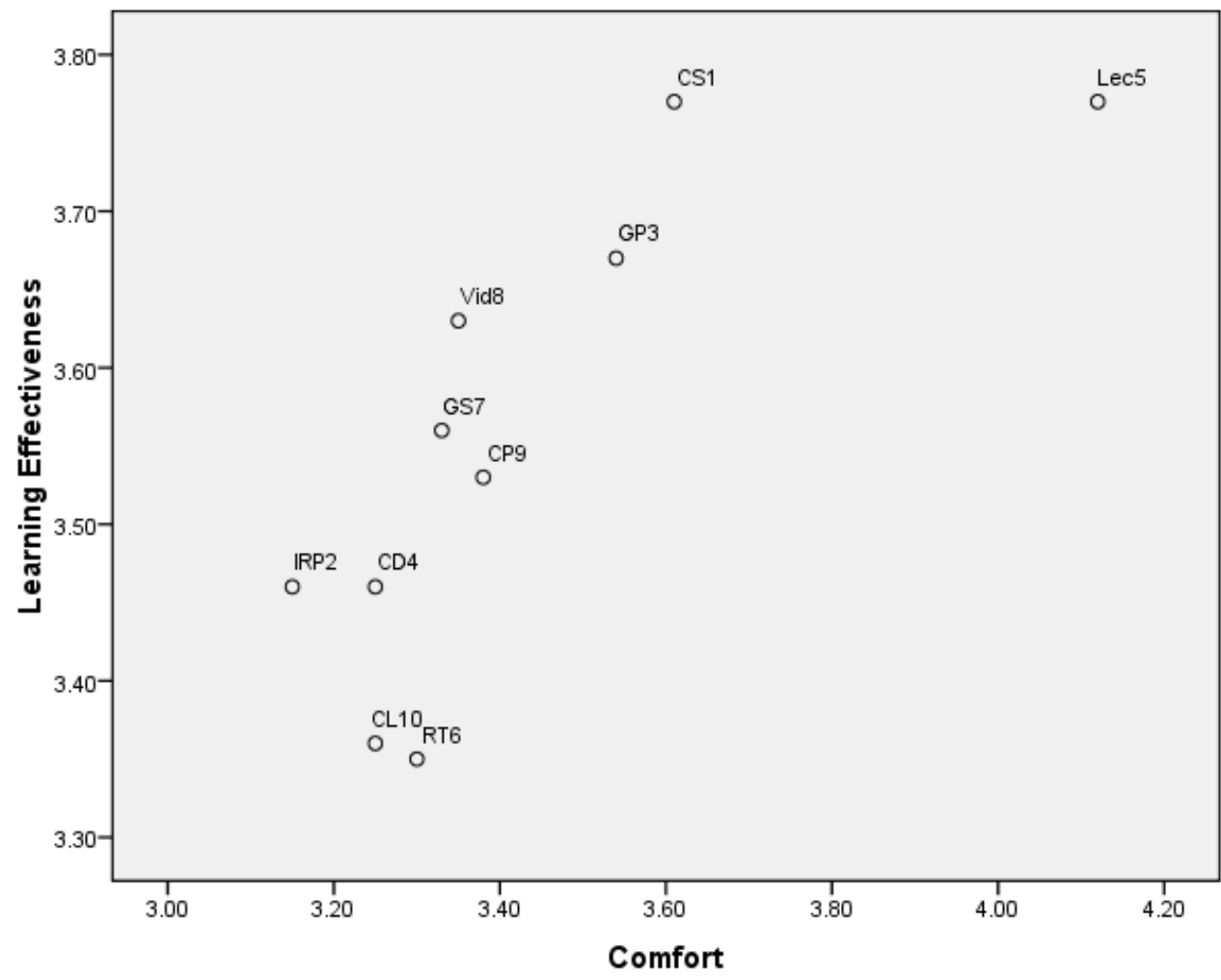

Figure 2: Learning Effectiveness and Comfort for Ten Instructional Techniques

('Lec5' - Lecture; 'CS1' - Case study; ‘GP3' - Group project; 'Vid8’ - Video; ‘GS7’ - Guest speakers; 'CP9' Classroom presentations; 'IRP2’ - Individual research project; ‘CD4' - Classroom discussion; ‘CL10’ -

Computerised learning; 'RT6' - Reading textbooks)

6.3.4 Perceived Learning Effectiveness and Familiarity

Familiarity had the second-highest correlation $(r=.564)$ with perceived learning effectiveness (Figure 4) indicating that the techniques most familiar to these students also were assumed to yield the greatest learning (again, lectures, case studies, and group projects) while techniques less familiar to them represented judgments of reduced learning (videos, guest speakers, classroom presentations, and more markedly reading texts and computerized learning [!]). Reading and extracting information textbooks and understanding its significance can be classified as generally challenging for all students all over the world regardless of the educational system. However, in today's rapid and highly technologically savvy climate, students' reports on computerized learning came as a surprise. This may be largely due to the lack of exposure to and awareness of such interactive and independent learning via e-technological platforms back in their country (China). This may also be due to the mixed population sample that includes students from varying provinces with differing stages of modernization and technological advancement.

Overall, students reported that they were most familiar with lectures, followed by group projects, case-studies, reading textbooks, classroom discussions, individual research, computerized learning, class presentation, guest speakers, while they were least familiar with videos. Not surprisingly, assessments ratings of familiarity were closely linked ( $\mathrm{r}=.759)$ to comfort. 


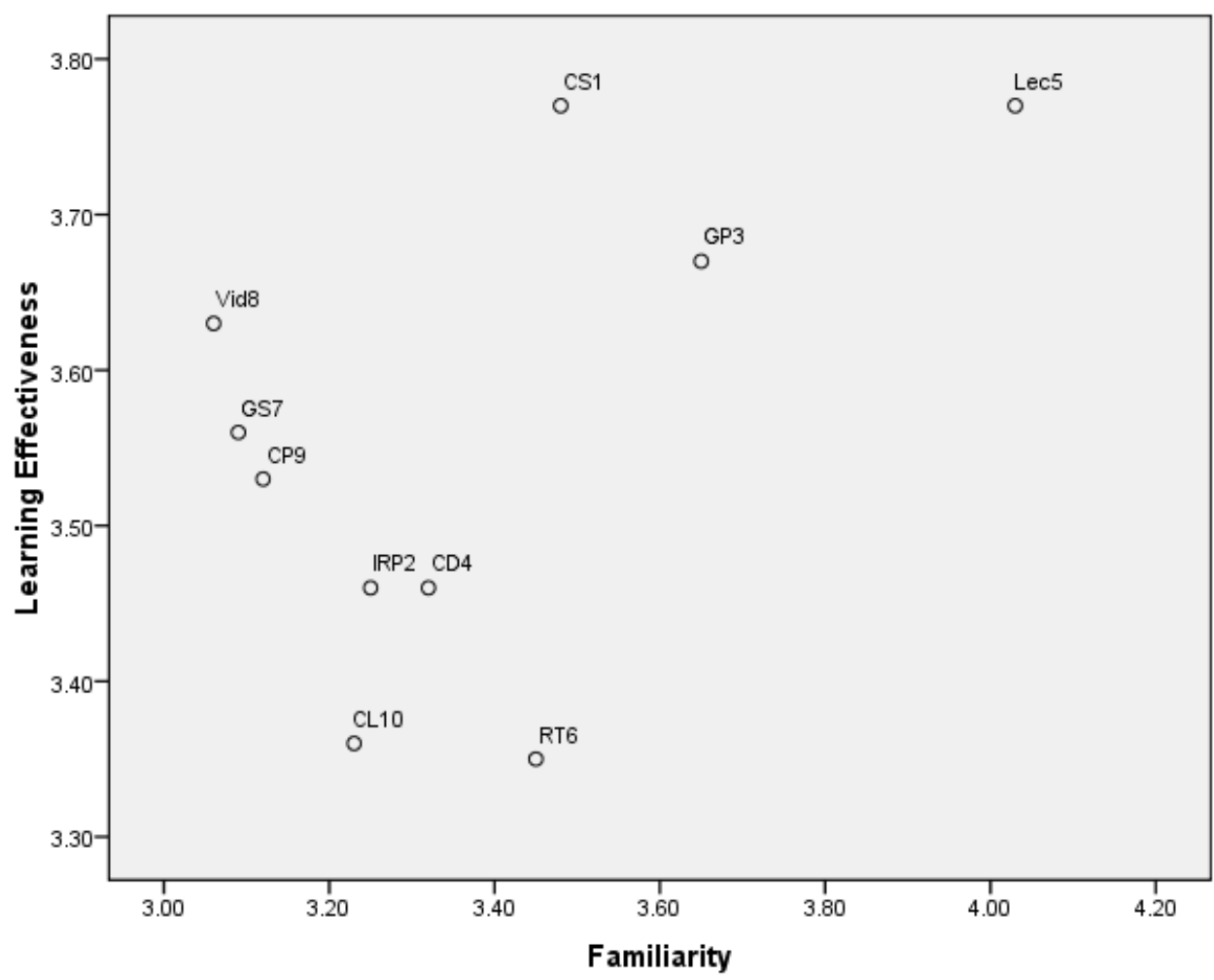

Figure 3: Learning Effectiveness and Familiarity for Ten Instructional Techniques

('Lec5' - Lecture; 'CS1' - Case study; 'GP3' - Group project; 'Vid8' - Video; 'GS7' - Guest speakers; 'CP9' Classroom presentations; 'IRP2' - Individual research project; 'CD4' - Classroom discussion; 'CL10' Computerised learning; 'RT6' - Reading textbooks)

\subsubsection{Learning Effectiveness and Ease of Knowledge Transfer}

Ease of knowledge transfer (from teacher to student) also correlated significantly ( $r=.526)$ with learning effectiveness, visibly so (Figure 5) for lectures and case studies and to a lesser degree for group projects and videos. In contrast, students judged classroom projects, individual research projects and reading texts to be less effective knowledge transfer activities, hence low in learning effectiveness.

Overall, they reported the greatest ease of knowledge transfer for lecturers, followed by case-studies, group projects, classroom discussions, videos, computerised learning, guest speakers, reading textbooks, individual research projects and with classroom presentations least of all. 


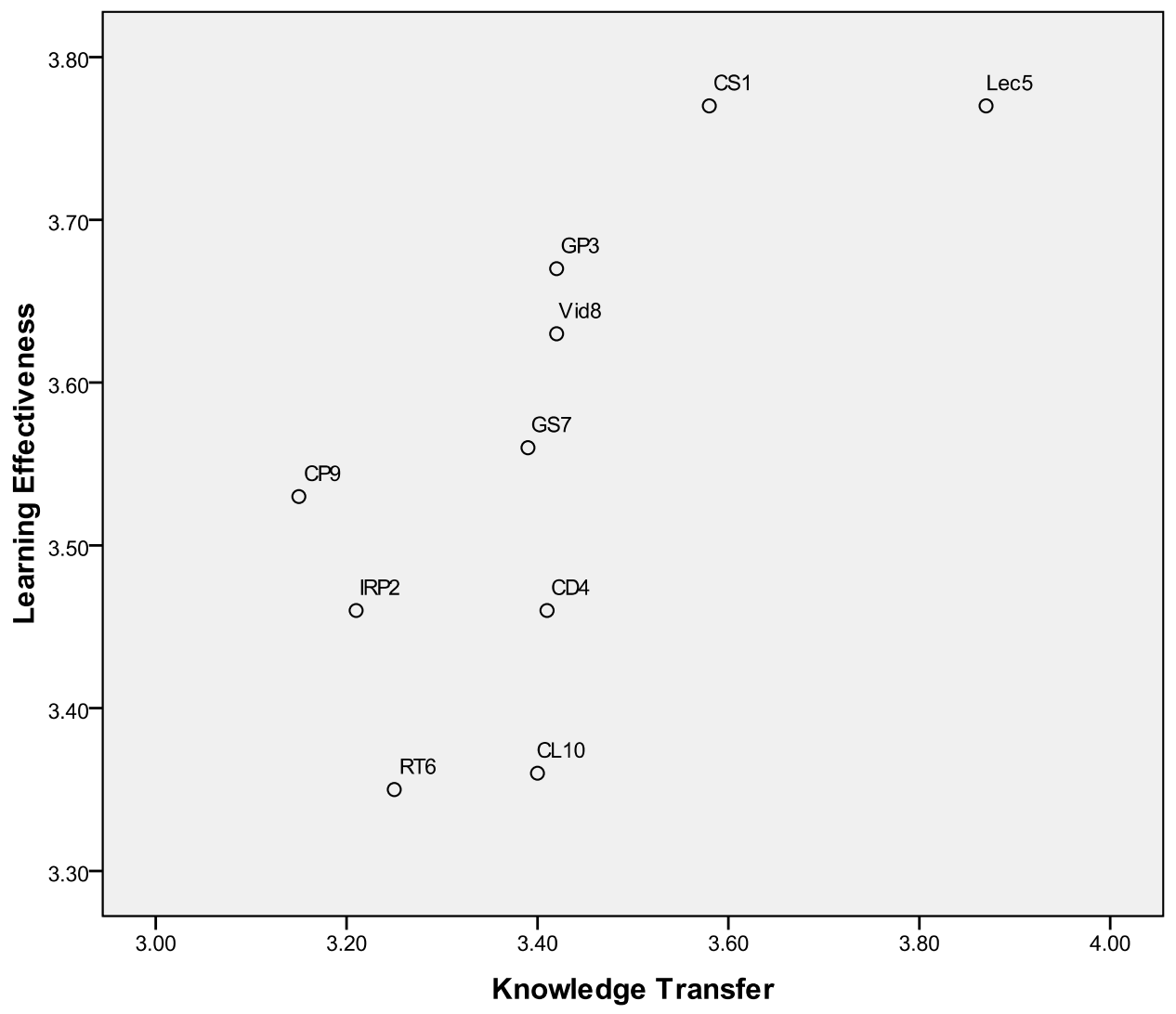

Figure 4: Learning Effectiveness and Knowledge Transfer for Ten Instructional Techniques

('Lec5' - Lecture; 'CS1' - Case study; 'GP3' - Group project; 'Vid8' - Video; 'GS7' - Guest speakers; 'CP9' Classroom presentations; 'IRP2' - Individual research project; 'CD4' - Classroom discussion; 'CL10' Computerised learning; 'RT6' - Reading textbooks)

On the face of it, learning effectiveness and knowledge transfer would seem to be equivalent concepts, however their differences become evident in the instructions to students about what they were to report. For knowledge transfer, students were to distinguish among the ten instructional techniques in terms of "easier, faster gaining and learning of knowledge". In contrast, learning effectiveness was a more complex construct characterized by about a dozen specific phrases including; "enhanced scope of knowledge", quality of learning", "efficient, effective learning”, "control over learning”, "gain more knowledge”, "increased awareness”, "enhanced effectiveness” and "applicability of learning”.

Students reported that two instructional techniques, classroom discussions and computerised learning enabled them to acquire knowledge with reasonable ease, but were not effective learning activities. Students' qualitative reports (that were conducted as an explorative study in earlier stage of the research) show that those techniques deterred them from acquiring content. This may be largely due to the mismatch on way these instructional techniques are being facilitated to fit the students' perceived engagement in terms of ease of acquiring of knowledge. For example, Shi (2006) reported that the Chinese learners "did not think having their own opinions was essential for a good learner” (pp. 138). This may be one of the reasons why class discussions and computerised learning may be rated highly in terms of ease of acquiring knowledge. Both require students to share their perspectives one (class discussions) in terms of verbal sharing and the other (computerized learning) in terms of written expression of thoughts, for example in specific learning platforms of discussion boards, forums and e-dialogue sessions. Similarly, their reports show that individual research projects and classroom presentations were classified as least effective for knowledge transfer but mid-range for overall perceived learning effectiveness. Other factors contributing to learning effectiveness (instructor's delivery style, level of student autonomy, instructors' cultural backgrounds) also warrant future research.

Clearly, learning effectiveness, comfort, familiarity and knowledge transfer are significantly interlocking concepts 
(Table 2) which correlate with learning effectiveness in that order (comfort=.61; familiarity=.56; and knowledge transfer $=.53$ ) and suggesting that in dislocated settings, learning effectiveness is mediated first by comfort, then familiarity, and thirdly by actual knowledge transfer.

6.3.6 Active vs Passive Instructional Techniques

Table 3 presents the comparative analysis of learning effectiveness versus comfort, familiarity and knowledge transfer ratings. It reports the students' ratings for four aspects of ten instructional techniques grouped according to Rodrigues' (2004) scheme.

Table 3: Comparisons of Learning Effectiveness, Comfort, Familiarity, and Knowledge Transfer Ratings for Ten Instructional Techniques Grouped by Rodrigues’ Scheme of Active/Passive

\begin{tabular}{|c|c|c|c|c|}
\hline $\begin{array}{l}\text { Instructional } \\
\text { Techniques } \\
\text { Active }\end{array}$ & $\begin{array}{c}\text { Learning } \\
\text { Effectiveness } \\
\text { Means rating } \\
\text { (Standard } \\
\text { Deviations) }\end{array}$ & $\begin{array}{c}\text { Comfort } \\
\text { Means rating } \\
\text { (Standard Deviations) }\end{array}$ & $\begin{array}{c}\text { Familiarity } \\
\text { Means rating } \\
\text { (Standard } \\
\text { Deviations) }\end{array}$ & $\begin{array}{c}\text { Knowledge } \\
\text { Transfer } \\
\text { Means rating } \\
\text { (Standard } \\
\text { Deviations) }\end{array}$ \\
\hline Case studies & $3.77(0.64)$ & $3.61(0.76)$ & $3.48(0.81)$ & $3.58(0.93)$ \\
\hline Individual research projects & $3.46(0.58)$ & $3.15(0.95)$ & $3.25(0.99)$ & $3.21(1.00)$ \\
\hline Group projects & $3.67(0.90)$ & $3.54(1.10)$ & $3.65(0.79)$ & $3.42(0.98)$ \\
\hline Classroom discussions & $3.46(0.70)$ & $3.25(1.05)$ & $3.32(0.96)$ & $3.41(1.02)$ \\
\hline Mean of active techniques & $3.59(0.70)$ & $3.39(0.96)$ & $3.43(0.89)$ & $3.41(0.98)$ \\
\hline \multicolumn{5}{|l|}{ Passive } \\
\hline Lectures by instructor & $3.77(0.73)$ & $4.12(0.89)$ & $4.03(0.94)$ & $3.87(0.95)$ \\
\hline Reading textbooks & $3.35(0.82)$ & $3.30(1.04)$ & $3.45(0.91)$ & $3.25(0.91)$ \\
\hline Guest speakers & $3.56(0.83)$ & $3.33(1.01)$ & $3.09(1.14)$ & $3.39(1.06)$ \\
\hline Videos & $3.63(0.70)$ & $3.35(1.03)$ & $3.06(1.16)$ & $3.41(0.99)$ \\
\hline Classroom presentations & $3.53(0.79)$ & $3.38(1.02)$ & $3.12(1.12)$ & 3.15 (1.17) \\
\hline Computerised learning & $3.36(0.75)$ & $3.25(1.08)$ & $3.23(1.14)$ & $3.40(0.99)$ \\
\hline Mean of passive techniques & $3.53(0.77)$ & $3.46(1.01)$ & $3.33(1.07)$ & $3.41(1.01)$ \\
\hline $\begin{array}{l}\text { Overall Means (SD) for } \\
\text { Ten Techniques }\end{array}$ & $3.56(0.55)$ & $3.43(0.31)$ & $3.37(0.298)$ & $3.39(0.21)$ \\
\hline $\begin{array}{l}\text { Significant Differences } \\
\text { Among Techniques }\end{array}$ & $\begin{array}{c}F=25.58, \mathbf{d f}=9, \\
p<.000\end{array}$ & $\begin{array}{l}F=43.27, \mathrm{df}=9, \\
p<.000\end{array}$ & $\begin{array}{l}=48.60, \mathrm{df}=9 \\
p<.000\end{array}$ & $\begin{array}{c}F=24.50, \mathbf{d f}=9, \\
p<.000\end{array}$ \\
\hline $\begin{array}{l}\text { Significant Differences } \\
\text { Between Active and } \\
\text { Passive Categories }\end{array}$ & 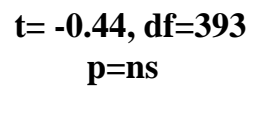 & $\begin{array}{cc}\mathbf{t}=-2.23, \mathbf{d f}=395 & \mathbf{t}= \\
\mathbf{p}<0.026 & \mathbf{p}<\boldsymbol{c}\end{array}$ & $\begin{array}{l}=3.60, \mathrm{df}=398 \\
<0.000\end{array}$ & $\begin{array}{l}t=-0.35, \mathrm{df}=394 \\
p=n s\end{array}$ \\
\hline
\end{tabular}

(Notes: Means and standard deviation ratings are computed where Strongly Disagree $=1$; Disagree $=2$; Neutral $=3$; Agree $=4$; Strongly Agree $=5$.)

The disparity of both ratings within Rodrigues' categories of active and passive is immediately apparent. Top rated and bottom rated techniques appear within both groups and cast suspicion on whether mainland Chinese students view such instructional techniques in the same way as Rodrigues' study groups. The active category was seen by students as significantly less comfortable and as significantly more unfamiliar than the passive (collective) category of instructional techniques.

The predominant view in the literature maintains that mainland Chinese students prefer passive teaching methods such as lectures, demonstrations, handouts, displays, films and videos (Nield, 2004). Experiential exercises, case studies, role-play and simulations belong to the participative teaching methods and are least preferred (Chow, 1995) and largely due to the cultural influence and students' prolonged exposure to the non-active and non-participative style of educational system since beginning high school but these results show no such differences in any of four different views of "preference" in the current study.

Studies which indicate that Chinese students prefer passive techniques were mostly performed in China and 
elsewhere decades ago. This may also largely due to studies' samples taken from lesser developed provinces and other intertwined social-demographic factors, whereas these students were pursuing their education in a Singapore cultural environment where a high level of Western educational influence exists. Some literature suggests that mainland Chinese students who achieve a higher level of cognitive learning outcomes are very closely supervised and guided, although it was reported that Chinese classrooms are different places when not seen through Western eyes (Biggs, 1994; Marton et. al., 1996; Tang, 1996). In contrast, recent studies (Ryan and Slethaug 2010; Clarke and Gieve 2006; Chan and Rao 2009; Shi 2006; Yang 2009) reports that Chinese learners are highly active; monitor their studies; learn from their mistakes or link past experiences to their studies; prefer a student-centered approach to a teacher-centered approach and are willing to participate in interactive and cooperative learning activities. However, to my best knowledge, none of these studies examine explicitly the perceived learning effectiveness across the commonly used instructional techniques. This further adds to the complexity as the style and approach on how these instructional techniques are put into practice differ in varying countries based on many reasons, of those some of them are, for example the influences from their economic, social, cultural and political phases.

The results from this research study shows preferences which range across the 'active' and 'passive' activities categorised by Rodrigues (2004). Several explanations are possible; (1) Mainland Chinese students are different from Rodrigues' international study groups, (2) Active/passive distinctions do not exist, or (3) differences among the techniques do exist, but not as Rodrigues has characterized them. Or students have changed and developed in their preferences as they experienced, became familiar with and adjusted to Singaporean assessment strategies. Cluster analysis of the ten techniques on the four learning aspects collectively confirms what the previous three figures hint at only individually; gross active/passive classification is too simplistic and fails to capture that Chinese students see these instructional techniques in more complex ways. Figure 5 shows that students see three such cluster groups, but that lectures retain their preeminent position in students' perception of effective teaching methods for learning, remaining unique in their learning experience. Least preferred (top) are the closely allied techniques of guest speakers, videos and classroom presentations; next are a second group of classroom discussions, computerized learning, individual projects and reading texts; while case studies and group projects are seen as a second-most preferred cluster. Lectures (bottom-most) however remain apart as the most effective, comfortable, familiar, and easiest route of knowledge transfer.

From this perspective, differences among the clusters of instructional techniques are statistically significant for all four learning aspects -- learning effectiveness ( $\mathrm{df}=3, \mathrm{~F}=31.02, \mathrm{p}<.001)$; comfort $(\mathrm{df}=3, \mathrm{~F}=113.49, \mathrm{p}<.000$ ); familiarity $(\mathrm{df}=3, \mathrm{~F}=28.80, \mathrm{p}<.001)$; and knowledge transfer $(\mathrm{df}=3, \mathrm{~F}=5.59, \mathrm{p}<.047)$. 


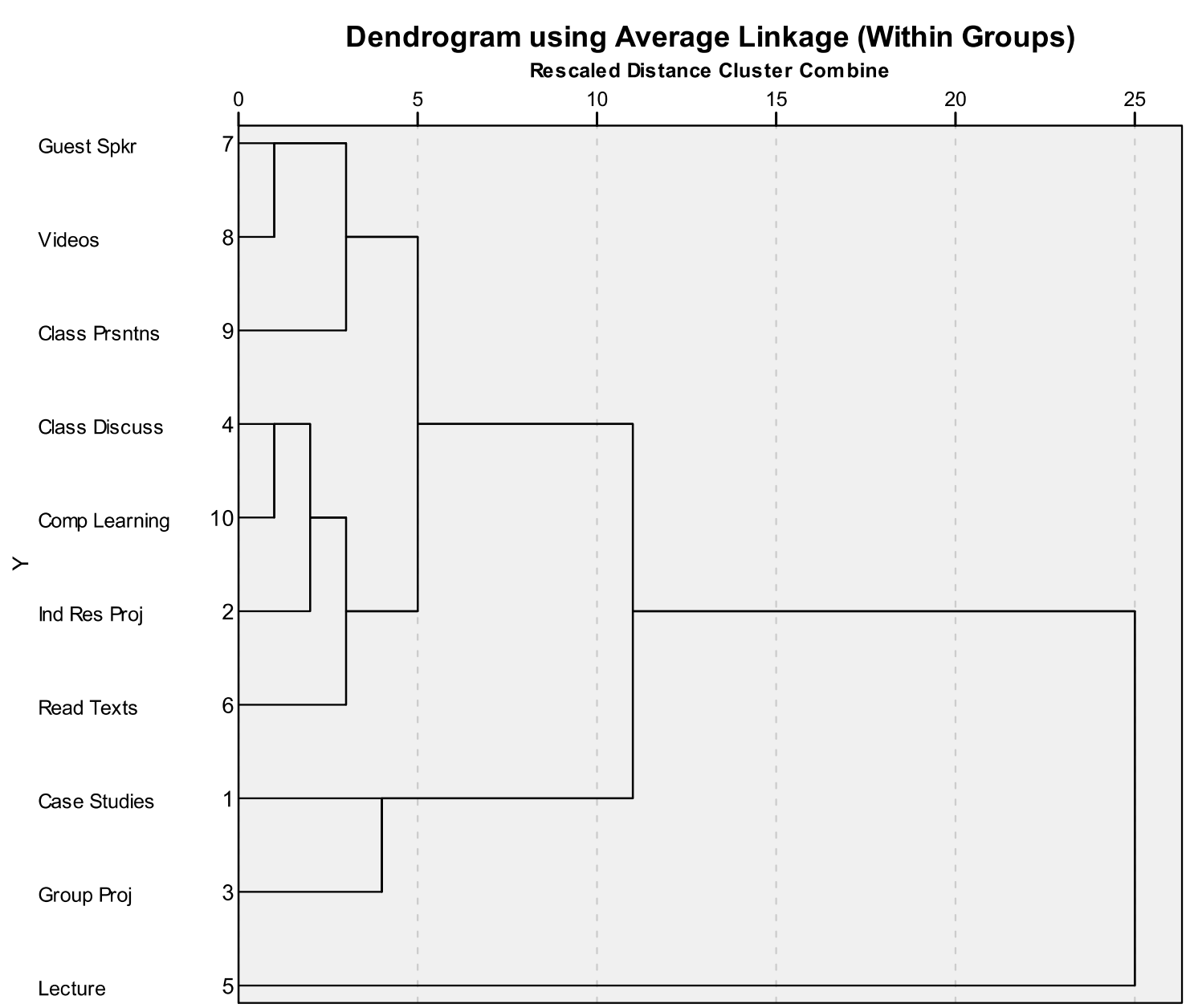

Figure 5: Mainland Chinese Students' Groupings of Ten Instructional Techniques on Simultaneous Criteria of Learning Effectiveness, Comfort, Familiarity, and Knowledge Transfer

Scholars (Aronson, 2002, Biggs 1994; Chow, 1995; Chan1999; Chan 1997; Clarke and Gieve, 2006; Cortazzi 2006; Chan and Rao, 2009; Coverdale-Jones and Rastall, 2009, Littlewood 2009; Ryan and Slethaug 2010; Rajaram, 2010; Rajaram and Bordia, 2011; Rajaram and Bordia, 2013; Shi 2006; Tang 1996; Turner, 2006 and Wen and Clement 2003;) have all provided evidence in the literature on learning method preferences for mainland Chinese learners. Few studies have been conducted about how effectively these students perceive to learn using specific (yet commonly used) groups of learning/teaching techniques that explicitly focus on a holistic coverage of a) to include a well balanced and mixed sample size which include students from varying cultural, social backgrounds, differing business programs, age and gender; b) western-based curriculum and teaching/learning approaches to be measured against in a cosmopolitan, developed with high influence of western values yet having the rooted CHC values country. The preference as what these students chose depending on their exposure, the type of assessment incorporated, long-established cultural and social values and norms (at least in the interim phases until they are fully adapted to the new learning cultures) and relative to their own personality type. But how these students learn effectively also differs depending on what type of learners they are for example more visual, cognitive, aural and kinesthetic (Fleming, et al., 1992) and on the processes involved in these instructional techniques to help them acquire information.

\section{Discussion}

Of the study's four research questions, three were positively responded, hence confirmed. Comfort (power distance), 
familiarity (uncertainty avoidance), and knowledge transfer (Confucianism) were all positively and significantly predictive of students' positive perceptions as to learning effectiveness - and of each other. However, Rodrigues' conjecture that some instructional techniques categorized as 'active' while others are 'passive' and the specific clusters being measured against to result in a higher level of learning was not supported - at least not among these Chinese business students. Among the ten instructional techniques, three emerged as perceived as distinctively effective as perceived by the students (see Table 4) - lectures, case studies, and group discussions across the four aspects of learning effectiveness, comfort, familiarity and knowledge transfer.

Table 4: Contrasts between Rodrigues' Active/Passive Classifications and Mainland Chinese Student Ratings of Effectiveness, Comfort, Familiarity, and Knowledge Transfer for Ten Instructional Techniques

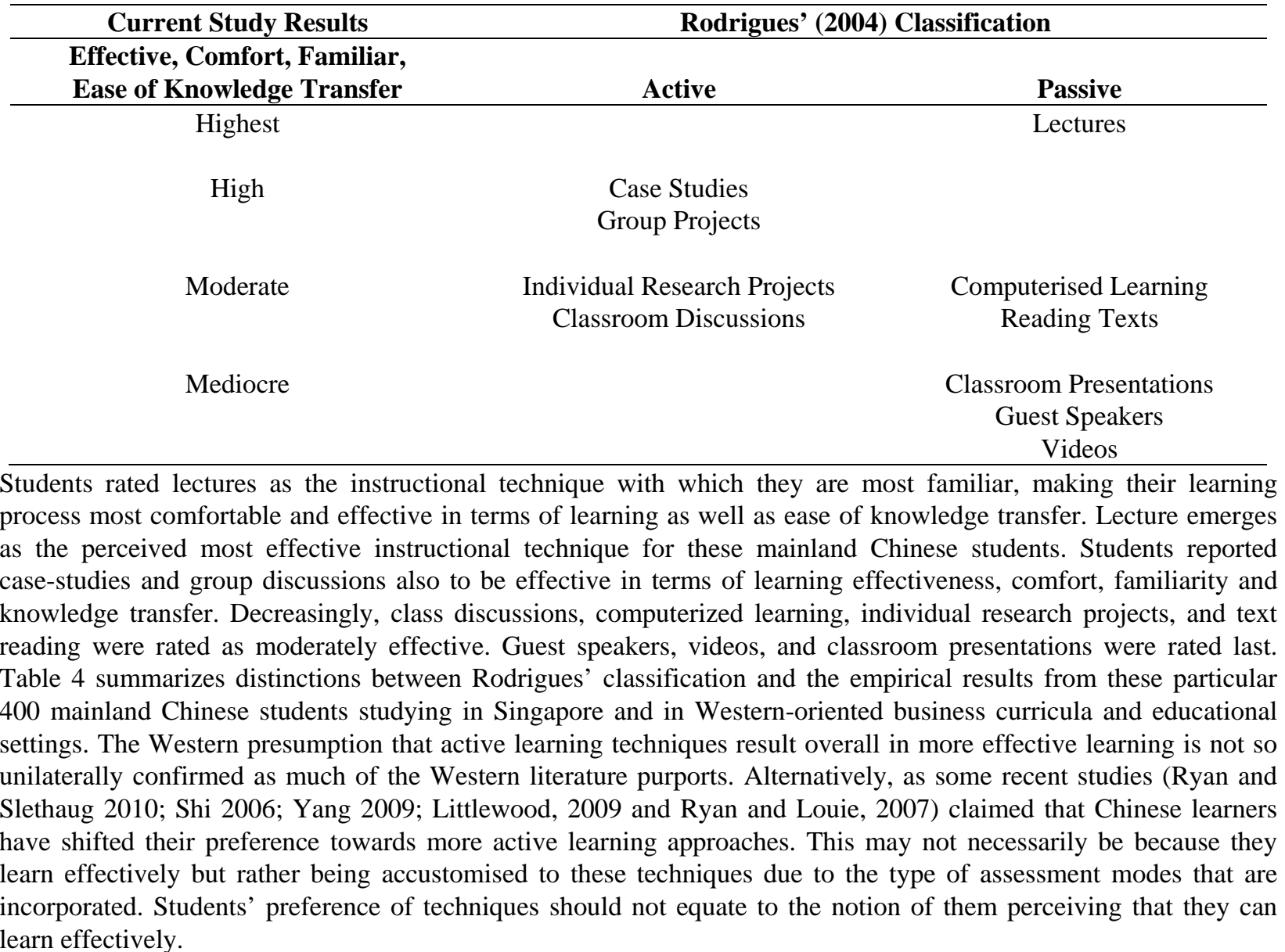

\section{Conclusion}

Having quality education targeted at diverse students from different foreign countries requires a good understanding of both cultural aspects and knowledge delivery. Central issues are: a) understanding the various teaching/learning techniques; and b) identifying the most appropriate mix of instructional techniques best suited to foreign students who represent different types of learners and varying learning preferences. This study serves as a bridging platform to address elements of cultural dislocation and learning effectiveness for mainland Chinese students.

The findings encourage teachers to continue to use a range of techniques, both those requiring active knowledge investigation and enquiry and those more geared to receptive knowledge transfers. Learners are likely to react to different methods according to a range of factors including the three cultural dislocation variables of comfort, familiarity and knowledge transfer have varying effects (Table 3) across the ten instructional techniques in terms of optimal learning effectiveness for these Chinese mainland students. Despite certain research limitations, the findings of this study prompt the following recommendations.

First, tutors should be creative and sensitive to students' individual learning needs and should adopt 
different instructional techniques (whether "active” or "passive”). This is to optimize learning even if these are not necessarily preferred (possibly due to the assessment modes) and learners may not be comfortable and familiar with them but perceived to learn from these techniques effectively.

Second, Chinese students prefer passive instructional techniques but do not necessarily learn most effectively or with optimal acquisition of knowledge.

Third, tutors should not generalize or incline towards adopting a specific cluster of instructional techniques (for example, the assumed connection between mainland Chinese students' preferences for 'passive' methods'. This preference is likely to be largely because of the widely used assessment modes, such as the traditional closed-book examination even now all over the countries, both Western and Asian developed and mature nations. Tutors should realize that no one instructional technique leads to optimally effective learning among Chinese students, but should rather recognize the varying learners' characteristics and should apply techniques appropriately in varying situations based on learners' prior knowledge, practical experiences, maturity level and cultural values/beliefs.

Having a clear understanding of the cultural dislocation elements and its effect on various instructional methodologies assists practitioners to design and deliver business curricula effectively. Globally, private schools as well as overseas universities will benefit from the findings presented in terms of developing their curricula and educational management strategies.

Although this study's main focus is on the learning effectiveness preferences of mainland Chinese students, its contributions address a larger perspective. Students' skills in making their learning effective, comfortable, familiar and readily transferable also influences their roles as future managers and their future performance in organisations eventually influences overall organisational growth which is a secondary contributing factor to any country's economy. Student ability to perform and deliver tangible results in corporate and national organisations depends on how well the knowledge has been transferred and acquired. Thus, moulding a quality pool of students eventually leads to developing successful business managers in the future.

\section{Acknowledgements}

The author wish to thank Adjunct Professor John B. Collins for his helpful advice on the paper. The author would also like to thank the anonymous reviewers and editors of the journal for providing valuable feedback and guidance on the paper.

\section{References}

Atkinson, D. (1997). A critical approach to critical thinking in TESOL. TESOL Quarterly, 31, 9-37. http://dx.doi.org/10.2307/3587975

Adler, N.J., Campbell, N., \& Laurent, A. (1989). In Search of appropriate methodology: From outside the People's Republic of China looking in. Journal of International Business Studies, 20, 61-74. http://dx.doi.org/10.1057/palgrave.jibs.8490351

Biggs, J. (1994). Asian learners through Western eyes: an astigmatic paradox. Australian and New Zealand Journal of Vocational Educational Research, 2(2), 40-63.

Biggs, J. (1996). Western misperceptions of the Confucian heritage learning culture, in Watkins, D.A. and Biggs, J.B. (Eds), The Chinese Learner: Cultural, Contextual and Psychological Influences, CERC and ACER, Hong Kong and Melbourne.

Bohm A., Davis D., Megres D., \& Pearce D. (2002). Global student mobility 2025: Forecasts of the global demand for International Higher Education. Sydney: IDP Education Australia.

Bond, M.H. (1992). Beyond the Chinese face: Insights from Psychology. Oxford University Press: Hong Kong.

Bodycott, P. (2009). Choosing a higher education study abroad destination: what mainland Chinese parents and students rate as important. Journal of research in International education, 8(3), 349-373. http://dx.doi.org/10.1177/1475240909345818

Bodycott, P., \& Lai, A. (2012). The influence and implications of culture in the decision to undertake higher education. Journal of studies in International education, 16(3), 252-270. 
http://dx.doi.org/10.1177/1028315311418517

Bu, N., \& Mitchell, V.F. (1992). Developing the PRC's managers: how can Western experts to be more helpful?. Journal of Management Development, 11(2), 42-53. http://dx.doi.org/10.1108/EUM0000000001394

Chan, S. (1991). Asian Americans: An Interpretative History. Twayne Publishers, Boston, MA.

Chan, M.W.L. (1996). Management education in the People's Republic of China. In Brown, D.H. and Porter, R. (Eds), Management Issues in China Domestic Enterprises, Vol. 1, Routledge, London.

Chan, S. (1999). The Chinese learner - a question of style. Education \& Training, 41(6/7), 294-304. http://dx.doi.org/10.1108/00400919910285345

Chan, D., \& Drover, G. (1997). Teaching and Learning for Overseas Students: the Hong Kong Connection, in McNamara, D. \& Harris, R. (eds) Overseas Students in Higher Education. London, Routledge.

Chan, C.K.K., \& Rao, N. (2009). Revisiting the Chinese Learner: Changing Education, Changing Context. Springer and the Comparative Education Research Centre, University of Hong Kong.

Chan, K. (2006). Consumer socialization of Chinese children in schools: analysis of consumption values in textbooks. Journal of Consumer Marketing, 23(3), 125-132. http://dx.doi.org/10.1108/07363760610663286

Carson, J., \& Nelson, G. (1996). Chinese students' perceptions of ESL peer response group Interaction. Journal of Second Language Writing, 5(1), 1-19. http://dx.doi.org/10.1016/S1060-3743(96)90012-0

Chan, D., \& Drover, G. (1997). Teaching and learning for overseas students: The Hong Kong connection. In D. McNamara \& R. Harris (Eds.), Overseas students in higher education (pp. 46-61). London: Routledge.

Carson, J. (1992). Becoming biliterate: First language influences. Journal of Second Language Writing, 1(1), 37-60. http://dx.doi.org/10.1016/1060-3743(92)90019-L

Clark, R., \& Gieve, S. N. (2006). On the Discursive Construction of 'The Chinese Learner'. Language, Culture and Curriculum, 19(1), 54-73. http://dx.doi.org/10.1080/07908310608668754

Chow, I.H.S. (1995). Management education in Hong Kong: needs and challenges. International Journal of Educational Management, 9, 10-15. http://dx.doi.org/10.1108/09513549510095068

Coverdale-Jones, T., \& Rastall, P. (2009). Internationalising the University: the Chinese context. Houndsmills: Palgrave Macmillan.

Chalmers, D., \& S. Volet (1997). Common misconceptions about students from South-East Asia studying in Australia. Higher Education Research and Development, 16(1), 87-101. http://dx.doi.org/10.1080/0729436970160107

Dejoy, J.K., \& Dejoy, D.M. (1987). Self-directed learning: the time is now. Training and Development Journal, 41(9), 64-6.

Dimmock, C., \& Walker, A. (1998). Transforming Hong Kong's schools: tends and merging issues. Journal of Educational Administration, 36(5), 476-491. http://dx.doi.org/10.1108/09578239810238465

Flowerdew, L. (1998). A cultural perspective on group work. ELT Journal, 52(4), 323-329. http://dx.doi.org/10.1093/elt/52.4.323

Fleming, N.D., \& Mills, C. (1992). Not Another Inventory, Rather a Catalyst for Reflection. To Improve the Academy, 11, 137-155.

Fox, H. (1994). Listening to the World. Urbana, IL: National Council of Teachers of English.

Gu, M. (2001). Education in China and abroad: Perspectives from a lifetime in comparative education. Hong Kong: Comparative Education Centre.

Geake, J., \& Maingard, C. (1999). NESB postgraduate students at a new university: 'Plus ça change, plus c'est la même chose. In Y.Ryan \& O. Zuber-Skerritt (Eds.), Supervising postgraduates from non-English speaking backgrounds (pp. 48-60). Buckingham: The Society for Research into Higher Education and Open University Press.

Hill, C.E., Thompson, B.J., \& Williams, E.N. (1997). A guide to conducting consensual qualitative research. The Counseling Psychologist, 25(4), 517-72.

Hill, C.E., S.A., Knox, S., Ladany, N., Thompson, B.J., \& Williams, E.N. (2005). Consensual qualitative research: an 
update. Journal of Counseling Psychology, 52(2), 196-205.

Hofstede, G. (1980). Culture's Consequences. Beverly Hills, C A: Sage.

Hofstede, G., \& Bond, M.H. (1988). The Confucian connection: from cultural roots to economic growth. Organizational Dynamics, 16(4), 5-21. http://dx.doi.org/10.1016/0090-2616(88)90009-5

Hofstede, G. (1991). Cultures and Organizations: Software of the Mind. McGraw-Hill, London.

Holland, R.P. (1989). Learner characteristics and learner performance: implications for instructional placement decision', in Shade, B.J.R. (Ed.), Culture, Style and the Educative Process, Charles C. Thomas Publisher, Springfield, IL, 167-83.

Hellmundt, S. (2001, December). The internationalisation of the tertiary curriculum: Strategies to link critical theory and intercultural understandings. Paper presented at the Australian Association for Research in Education conference, Fremantle.

Hu, G. W. (2003). English language teaching in China: Regional differences and contributing factors. Journal of Multilingual and Multicultural Development, 24(4), 290-318. http://dx.doi.org/10.1080/01434630308666503

Jarrah, F. (1998). New courses will target transition to university. China Morning Post, 23(April), 28.

Johnson, H. (1991). Cross-cultural differences: Implications for management education and training. Journal of European Industrial Training, 15(6), 13-16. http://dx.doi.org/10.1108/03090599110137615

Jin, L., \& Cortazzi, M. (2006). Changing Practices in Chinese Cultures of Learning. Language, Culture and Curriculum, 1(1), 5-20. http://dx.doi.org/10.1080/07908310608668751

Jones, J. (1999). From silence to talk: cross-cultural ideas on students' participation in academic group discussion. English for Specific Purposes, 18(3), 24-259. http://dx.doi.org/10.1016/S0889-4906(97)00059-8

Kemp L. (2010). Teaching \& Learning for International students in a Learning Community: Creating, sharing and building knowledge. Journal of Scholarly Teaching, 5, 64-74.

Kolb, D. A., \& Fry, R. (1975). Toward an applied theory of experiential learning. In C. Cooper (Ed.), Studies of group process, New York: John Wiley \& Sons, 33-57.

Kumaravadivelu, B. (2003). Problematizing culture stereotypes in TESOL. TESOL Quarterly, 37(4), 709-716. http://dx.doi.org/10.2307/3588219

Littlewood, W. (2009). Participation-based pedagogy: How congruent is it with Chinese cultures of learning? In P.Cheng and J.X. Yan (Eds.), Cultural Identity and Language anxiety, Guilin: Guangxi Normal University Press, 179-202.

Ladd, P.D., \& Ruby, R. Jr. (1999). Learning style and adjustment issues of international students. Journal of Education in Business, 74(6), 363-7. http://dx.doi.org/10.1080/08832329909601712

Lindsay, C.P., \& Dempsey, B.L. (1983). Ten painfully learned lessons about working in China: the insights of two American behavioral scientists. Journal of Applied Behavioral Science, 19(2), 265-76. http://dx.doi.org/10.1177/002188638301900305

Liu, S. (2006). Developing China's future managers: learning from the West? Education \& Training, 48(1), 6-14. http://dx.doi.org/10.1108/00400910610645699

Li, J. (2001). Chinese conceptualization of learning. Ethos, 29, 111-137. http://dx.doi.org/10.1525/eth.2001.29.2.111

Littlewood, W. (2009). Participation-based pedagogy: How congruent is it with Chinese cultures of learning? In P.Cheng and J.X. Yan (Eds.), Cultural Identity and Language anxiety, Guilin: Guangxi Normal University Press, 179-202.

Littlemore, J. (2001). The use of metaphor in university lectures and the problems that it causes for overseas students. Teaching in Higher Education, 6(3), 333-49. http://dx.doi.org/10.1080/13562510120061205

Lum L. (2006). Internationally-educated health professionals: a distance education multiple cultures model. Education \& Training, 48(2/3), 112-126. http://dx.doi.org/10.1108/00400910610651755

Louie, K. (2005). Gathering cultural knowledge: Useful or use with care? In J. Carroll \& J. Ryan (Eds), Teaching International students: Improving learning for all (pp. 17-25), London: Routledge Falmer.

Martinsons, M.G., \& Martinsons, A.B. (1996). Conquering cultural constraints to cultivate Chinese management 
creativity and innovation. Journal of Management Development, 15(9), 18-35. http://dx.doi.org/10.1108/02621719610146239

Marton, F., Dall'Alba, G., \& Tse, L.K. (1996). Memorizing and understanding: The keys to the paradox? in Watkins D. A \& Biggs J.B (Eds), The Chinese Learner: Cultural, psychological and contextual influences. Melbourne and Hong King: Australian Council for Educational Research and the Comparative Education Research Centre, University of Hong Kong, 69-84.

Morey D., \& Frangioso, T. (1998). Aligning an organization for learning - The six principles of effective learning. Journal of Knowledge Management, 1(4), 308-214. http://dx.doi.org/10.1108/EUM0000000004602

Nakamura, H. (1964). Ways of Thinking of Eastern People. University of Hawaii Press, Honolulu, HI.

Newell S. (1999). The transfer of management knowledge to China: building learning communities rather than translating Western textbooks? Education + Training, 41(6/7), 286-294.

Nelson, G. (1995). Cultural differences in learning styles. In J. Reid (ed.). Learning styles in the ESL/EFL classroom, 3-18. Boston, MA: Heinle \& Heinle.

Nield K. (2004). Questioning the myth of the Chinese learner. International Journal of Contemporary Hospitality Management, 16(3), 189-196. http://dx.doi.org/10.1108/09596110410531186

Nisbett R.E. (2003). The geography of thought. New York: Simon \& Schuster.

Ninnes, P., Aitchison, C., \& Kalos, S. (1999). Challenges to stereotypes of international students' prior educational experience: undergraduate education in India. Higher Education, Research and Development, 18(3), 323-342. http://dx.doi.org/10.1080/0729436990180304

Oxford, R. (1995). A cross cultural view of learning styles. Language Teaching, 28, 201-15. http://dx.doi.org/10.1017/S0261444800000446

Pun, A.S.L. (1989a). Developing managers internationally: culture free or culture bound, symposium presentation at the Conference on International Personnel and Human Resource Management, Hong Kong, 13 December.

Rajaram, K. (2013, in Press). Followers of Confucianism or a New Generation? Learning culture of mainland Chinese: in pursuit of western based business education away from mainland China. International Journal of Teaching \& Learning in Higher Education, 25(3).

Rajaram, K., \& Bordia, S. (2013). East versus West: Effectiveness of knowledge acquisition and impact of cultural dislocation issues for mainland Chinese students across ten commonly used instructional techniques. International Journal for the Scholarship of Teaching and Learning, 7(1), 1-21.

Rajaram, K., \& Bordia, S. (2011). Culture Clash: teaching Western-based management education to mainland Chinese students in Singapore. Journal of International Education in Business, 4(1), 63-83. http://dx.doi.org/10.1108/18363261111170595

Rajaram, K. (2010). Culture Clash: teaching western-based business education to mainland Chinese students in Singapore, Thesis (PhD), University of South Australia.

Redding, G. (1990). The spirit of Chinese Capitalism. Walter deGuyter, New York, NY.

Rodrigues C.A. (2004). The importance level of ten teaching/learning techniques as rated by university business students and instructors. Journal of Management Development, 23(2), 169-182. http://dx.doi.org/10.1108/02621710410517256

Ryan, J., \& Slethaug, G. (2010). International Education and the Chinese Learner. Hong Kong University Press, 13-89.

Ryan J., \& Louie K. (2007). False Dichotomy? 'Western' and 'Confucian' concepts of scholarship and learning. Educational Philosophy \& Theory, 39(4), 404-417. http://dx.doi.org/10.1111/j.1469-5812.2007.00347.x

Ryan, J., \& S. Hellmundt (2005). Maximising international students' 'cultural capital'. In Teaching International Students: Improving Learning for All. J. Carroll and J. Ryan. London, Routledge: 13-16.

Ryan, J. (2005). Improving teaching and learning practices for international students: Implications for curriculum, pedagogy and assessment. Teaching International Students: Improving Learning for All. J. Carroll and J. Ryan. London, Routledge: 92-100.

Ryan, J. (2005). Postgraduate supervision. Teaching International Students: Improving Learning for All. J. Carroll 
and J. Ryan. London, Routledge: 101-5.

Shi L. (2006). The successors to Confucianism or a new generation? A questionnaire study on Chinese students' culture of learning English. Language, Culture and Curriculum, 19(1), 122-147. http://dx.doi.org/10.1080/07908310608668758

Shade, B. J.R. (1989b). Culture: The key to adaptation', in shade, BJ.R. (Ed), Culture, style and the educative process. Charles C. Thomas Publisher, Springfield, IL, 9-15.

Tan, J. (2011). Revisiting the Chinese learner: changing contexts, changing education. Asia Pacific Journal of Education, 31(2), 227-228. http://dx.doi.org/10.1080/02188791.2011.581866

Tang, C. (1996). Collaborative learning: The latent dimension in Chinese students' learning. In D. A. Watkins \& J. B. Biggs (Eds.), The Chinese Learner: Cultural, Psychological and Contextual Influences, (pp. 183-205). Hong Kong: Comparative Education Research Center.

Thompson, E.R., \& Gui, Q. (2000). The appropriateness of using Hong Kong to make inferences about business students in Mainland China. Journal of Education for Business, September/October, 48-56. http://dx.doi.org/10.1080/08832320009599050

Tsang, E.W.K. (2001). Adjustment of mainland Chinese academics and students to Singapore. International Journal of Intercultural Relations, 25, 347-372. http://dx.doi.org/10.1016/S0147-1767(01)00010-4

Turner, Y. (2006). Chinese students in UK business school: Hearing the student voice in reflective teaching and learning. Higher Education Quarterly, 60, 27-51. http://dx.doi.org/10.1111/j.1468-2273.2006.00306.x

Tweed, R. G., \& Lehman, D. R. (2002). Learning considered within a cultural context: Confucian and Socratic approaches. American Psychologist, 57(2), 89-99. http://dx.doi.org/10.1037/0003-066X.57.2.89

Tweed, R.G., \& Lehman, D. R. (2003). Confucian and Socratic learning. American Psychologist, 58(2), 148-149. http://dx.doi.org/10.1037/0003-066X.58.2.148

Vygotsky, L. S. (1997). Interaction Between Learning and Development. In M. Gauvain, \& M. Cole (Eds.), Readings on the Development of Children (2nd ed., pp. 79-91). Cambridge, MA: Harvard University Press.

Vygotsky, L. S. (2004). Imagination and Creativty in Childhood. Journal of Russian and East European Psychology, 42(1), 7-97.

Warner, M. (1991). How Chinese managers learn. Journal of General Management, 16(4), 66-84.

Wen, W.P., \& Clement, R. (2003). A Chinese conceptualisation of willingness to communicate in ESL. Language, Culture and Curriculum, 16(1), 18-38. http://dx.doi.org/10.1080/07908310308666654

Watkins, D. (1996). Learning theories and approaches to research: a cross-cultural perspective. In Watkins, D. \& Biggs, J.B. (eds.), The Chinese Learners: Cultural, Psychological and Contextual Influences. Melbourne and Hong Kong: ACER \& CERC.

Watkins, D. (2001). Correlates of approaches to learning: A cross-cultural meta-analysis. In R. J. Sternberg \& L. F. Zhang (eds.), Perspectives on thinking, learning and cognitive styles. London: LEA.

Watkins, D., \& Biggs, J.B.(2001). The paradox of the Chinese learner and beyond. In D. Watkins \& J.B. Biggs (eds.) Teaching the Chinese learner. Hong Kong: CERC.

Witkins, H.A., Moore, C.A., Goodenough, D.R., \& Cox, P.W. (1977). Field-dependent and field-independent cognitive styles and their educational implications. Review of Educational Research, 47(1), 1-64. http://dx.doi.org/10.3102/00346543047001001

Yang, Z. (2009). The effect of mother tongue transfer on English writing. Teaching and Management, 11(3), 16-20.

Yao, X. (2000). An Introduction to Confucianism. Cambridge: CUP. http://dx.doi.org/10.1017/CBO9780511800887 